\title{
Pulpotomía en dentición primaria: un análisis bibliométrico de 57 años.
}

\author{
Nathalia P. Reynoso, ${ }^{1}$ (D) Ana M. Leyda, ${ }^{2}$ (1) Marta Ribelles. ${ }^{3}$ (D)
}

\begin{abstract}
Resumen: Introducción: La pulpotomía es el tratamiento pulpar más frecuentemente realizado en dentición primaria pero aún no se ha elaborado un análisis bibliométrico de la literatura científica publicada al respecto. Objetivo: Conocer el desarrollo de los artículos publicados sobre pulpotomía en dientes primarios desde 1960 hasta el 2017. Material y métodos: Se realizó una búsqueda bibliográfica electrónica incluyendo artículos en inglés, disponibles a texto completo en versión electrónica. Los indicadores bibliométricos analizados fueron: distribución cronológica de los documentos, productividad por revistas, por autores, por países, por instituciones, por tipo de artículo, por contenido temático, número de autores/ artículo, número de citas recibidas/artículo y número de referencias bibliográficas empleadas/artículo. Resultados: Se incluyeron 204 artículos publicados en 39 revistas, sólo un tercio especializadas en odontopediatría. El 80,23\% de los primeros firmantes estaba vinculado a una universidad. El número medio de autores/artículo fue de 2,85 de 30 países diferentes. El $50 \%$ de los trabajos fueron estudios clínicos no aleatorizados y el $82,84 \%$ buscó el mejor material para tratar la pulpa radicular remanente. Los países con mayor número de publicaciones fueron Estados Unidos $(n=40)$ e India ( $n=38)$. Conclusiones: La producción de artículos sobre pulpotomía en dentición primaria y el número de revistas donde fueron publicados aumentó progresivamente en las décadas estudiadas, así como el número de autores firmantes. Predominaron los estudios clínicos buscando la mejor alternativa para tratar la pulpa remanente. El principal lugar de investigación fueron las universidades. Los paises emergentes han ganado protagonismo en la producción científica mundial sobre el tema analizado.
\end{abstract}

Palabras clave: análisis bibliométrico, pulpotomía, dentición primaria.

\section{Pulpotomia em dentição primária: uma análise bibliométrica de 57 anos.}

\begin{abstract}
Resumo: Introdução: A pulpotomia é o tratamento mais frequentemente realizado em dentição temporária mas não foi ainda efetuada uma análise bibliométrica da literatura científica publicada a respeito. Objetivo: Conhecer o desenvolvimento dos artigos publicados sobre pulpotomia em dentes primários desde 1960 até 2017. Material y método: Realizou-se uma pesquisa bibliográfica eletrônica a incluir: artigos em inglês, disponíveis a texto integral em versão eletrônica. Os indicadores bibliométricos foram: distribuição cronológica dos documentos, produtividade por revistas, por autores, por países, por instituições, por tipos de artigos, por conteúdo temático, número de autores por artigo, número de citações recebidas por artigo e número de referências bibliográficas utilizadas em cada artigo. Resultados: Foram incluídos 204 artigos publicados em 39 revistas, apenas um terço delas especializadas em odontopediatria. 80,23\% dos primeiros autores estavam ligados a uma universidade. O número médio de autores/artigo foi 2,85 de 30 países diferentes. $50 \%$ dos trabalhos foram estudos clínicos não ramdomizados e $82,84 \%$ procurava o melhor material para o tratamento da polpa radicular remanescente. Os países com maior número de publicações foram os Estados Unidos $(n=40)$ e a Índia $(n=38)$. Conclusões: A produção de artigos sobre pulpotomia em dentição temporária e o número de revistas onde foram publicados aumentou progressivamente nas décadas estudadas assim como o número de autores assinantes. Predominaram os estudos clínicos em busca da melhor alternativa para o tratamento da polpa radicular vital. O principal local de pesquisa foram as universidades. Os países emergentes ganharam protagonismo na produção científica mundial sobre o tema analisado.
\end{abstract}

Palabra-chave: bibliometria, pulpotomia, dentição temporária.

\footnotetext{
1 Odontopediatra. Práctica privada

2 Profesora asociada del Máster en Odontopediatría Integral de la Universidad CEU-Cardenal Herrera (Valencia, España).

3 Profesora Coordinadora del Máster en Odontopediatría Integral, Profesora Responsable de Odontopediatría (I y II) del Grado de Odontología de la Universidad CEUCardenal Herrera (Valencia, España).
} 


\title{
Pulpotomy in primary dentition: a 57-bibliometric analysis.
}

\begin{abstract}
Introduction: Pulpotomy is the pulp treatment most frequently performed in primary dentition, but a bibliometric analysis of the scientific literature on the subject has not yet been carried out. Objective: To know the development of published articles on pulpotomy in primary teeth from 1960 to 2017. Material and methods: an electronic bibliographic search was performed including articles in English, available in full text in electronic version. The bibliometric indicators analyzed were: chronological distribution of the documents, productivity by journals, by authors/article, by countries, by institutions, by type of article, by thematic content, number of authors/article, number of citations received/article and number of bibliographic references. Results: 204 articles published in 39 journals were included, only one third were specialized in Pediatric Dentistry. Of the first signatories, $80.23 \%$ were linked to a university. The mean number of authors/article was 2.85 from 30 different countries. Fifty percent of the papers were non-randomized clinical studies and $82.84 \%$ sought the best material to treat the remaining root pulp. The countries with the highest number of publications were the United States $(n=40)$ and India $(n=38)$. Conclusions: The production of articles on pulpotomy in primary dentition and the number of journals where they were published increased progressively in the decades studied, as did the number of authors. Clinical studies were predominant in the search for the best alternative for the treatment of the remaining pulp. The main place of the research were universities. Emerging countries have gained prominence in world scientific production on the analyzed subject.
\end{abstract}

Key words: bibliometric analysis, pulpotomy, primary dentition.

\section{Introducción}

La pulpotomía es el tratamiento pulpar más comúnmente realizado en la dentición primaria (DP). Consiste en la amputación de la pulpa coronal inflamada y el tratamiento del tejido pulpar radicular remanente para preservar su vitalidad, facilitando así la exfoliación del diente tratado en su momento cronológico correcto..$^{1-3}$

Las investigaciones realizadas en los últimos 50 años sobre pulpotomía en DP son metodológicamente diversas, centrándose por un lado en la búsqueda de los mejores productos para el tratamiento del tejido pulpar radicular vital remanente, y por otro en la exploración de nuevos enfoques para el tratamiento de las lesiones profundas de caries. Sin embargo, aún no se ha llevado a cabo un análisis exhaustivo del conjunto de la literatura existente sobre el tema desde un punto de vista bibliométrico.
La bibliometría estudia, clasifica y evalúa la producción y el consumo científico mediante métodos cuantitativos y tratamiento estadístico. ${ }^{4-8}$ Los métodos bibliométricos permiten conocer y analizar a los productores, los procesos y la evolución de la investigación mediante indicadores para su posterior análisis. ${ }^{8,9}$ Es una herramienta capaz de determinar los fenómenos y tendencias que se producen en el campo científico a partir de su literatura. ${ }^{10}$

En odontología se han realizado estudios bibliométricos en diversas áreas, ${ }^{11,12}$ incluida la odontopediatría, ${ }^{13-15}$ sin embargo dentro del área odontopediatrica la producción científica en relación a la pulpotomía en DP aún no ha sido analizada desde este punto de vista, lo que sin duda ayudaría a visibilizar los esfuerzos de los investigadores para evaluar y encontrar soluciones a las cuestiones abiertas en el campo de la terapia pulpar vital en 
DP. ${ }^{16}$ Estamos en un punto de inflexión histórica en el que es necesario recoger los conocimientos construidos hasta ahora con una mirada crítica, pero también de futuro sobre lo que es más adecuado, ético, pertinente y seguro para el tratamiento de dientes primarios con compromiso pulpar. Por este motivo, se realizó un análisis bibliométrico de los artículos publicados sobre pulpotomía en DP entre 1960 y 2017 con el objetivo de conocer de forma global el desarrollo de la investigación publicada al respecto en ese periodo de tiempo.

\section{Material y métodos}

Al tratatarse de un análisis bibliométrico este estudio no necesitó la autorización por parte de ningún Comité de Ética.

\section{Búsqueda bibliográfica}

En noviembre de 2017 se realizó una búsqueda bibliográfica electrónica de artículos publicados sobre pulpotomía en DP en inglés en las bases de datos científicas PubMed (https://www.ncb. nlm.nih.gov/pubmed), Web of Science (WoS) (todas las bases de datos, http:// apps.webofknowledge.com), $\quad$ Scopus (https://www.scopus.com/home.uri) y Cochrane Library (https://cochranelibrary. com). Se utilizaron combinaciones de palabras del vocabulario de terminología controlada para artículos (MeSH) junto con los operadores booleanos AND y OR: "pulpotomy", "materials AND pulpotomy", "pulpotomy in primary teeth", "pulpotomy for molars", "pulpotomy review", "pulpotomy formocresol", "pulpotomy laser", "pulpotomy MTA", "biodentine pulpotomy", "ferric sulfate pulpotomy", "hypoclorite pulpotomy", "calcium hydroxide pulpotomy", "pulpotomy deciduous" y "pulpotomy pediatric dentistry".

La búsqueda inicial arrojó un total de 5.692 resultados.

Criterios de inclusión y tamaño de la muestra

Como criterio de inclusión se estableció: Artículos sobre pulpotomía en DP en inglés publicados entre 1960 y 2017 disponibles a texto completo en formato electrónico. Se excluyeron las cartas al editor, los editoriales o la publicación de resúmenes.

Atendiendo a estos criterios se limitó la búsqueda en el tiempo (1960-2017) y se leyó el título y resumen de los resultados obtenidos. Dos investigadoras independientes descartaron 5.336 trabajos de los 5.692 obtenidos inicialmente, bien por no estar dentro de las fechas establecidas o bien por no referirse a pulpotomía en DP. Se seleccionaron 356 ítems, comprobando que ninguno estuviera duplicado. Después las dos investigadoras de manera independiente leyeron los artículos a texto completo y verificaron que cumplían los criterios de inclusión. Las diferencias de opinión se resolvieron por consenso y cuando esto no fue posible, se consultó a una tercera investigadora. En atención a los criterios de inclusión, se descartaron 167 documentos por no referirse a pulpotomía en DP. Además, se incorporaron 15 artículos tras la revisión de las listas bibliográficas de los trabajos seleccionados (Figura 1). La muestra quedó constituida por 204 artículos (Anexo 1). 


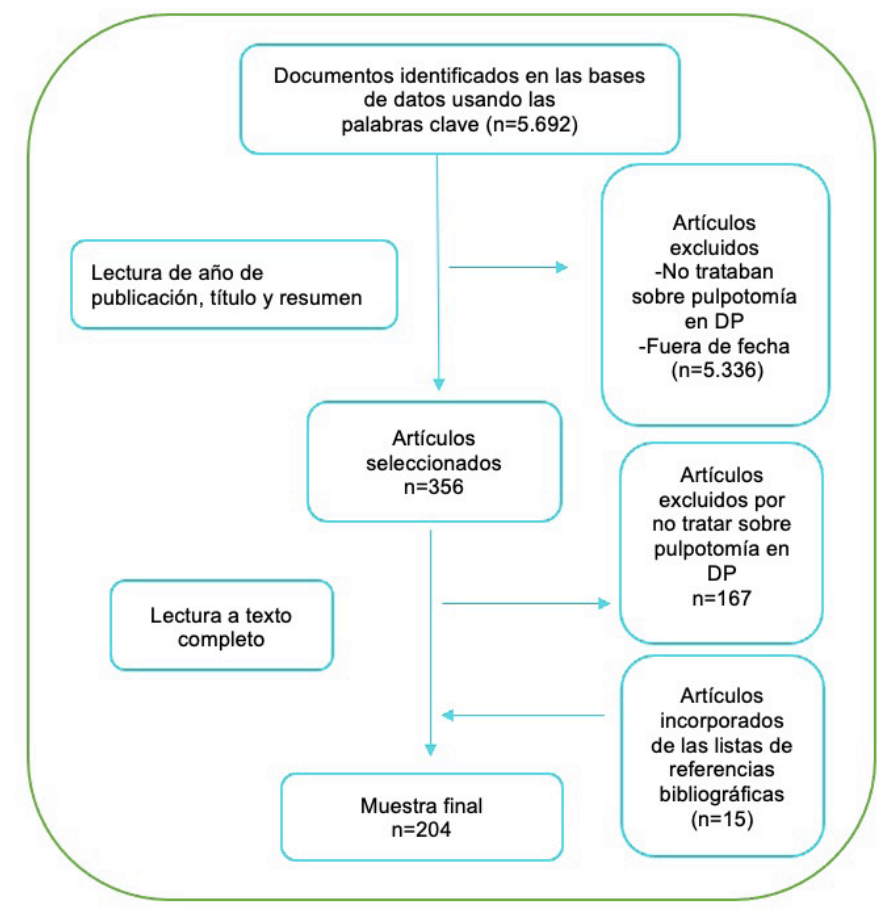

Figura 1. Esquema de la selección de los artículos para la muestra del estudio.

Organización de la información y tratamiento de los datos

Los 204 artículos seleccionados se organizaron por décadas y las dos investigadoras extrajeron de forma independiente los datos necesarios. Las diferencias que surgieron se resolvieron por consenso. En caso de no alcanzarlo se consultó con una tercera investigadora. Los datos extraídos fueron los necesarios para realizar un análisis bibliométrico clásico utilizando como indicadores: 1) la distribución cronológica de los documentos, 2) la productividad por revistas, 3) por autores,4)porpaíses, asignandoaldocumento el país de la institución del primer autor firmante 5) por instituciones: hospitales, universidades, centros de investigación, centros dentales y consultorios privados, 6) por tipo de artículo: revisión narrativa, estudio in vitro, estudio en animales, caso clínico, series de casos, ensayos de casos y controles, estudios de cohortes, ensayos clínicos no aleatorizados (EINA), ensayos clínicos aleatorizados (ECA), guías clínicas y revisiones sistemáticas con o sin metaanálisis, 7) por contenido temático: terapia pulpar en DP, pulpotomía en DP, guías clínicas, tratamiento del tejido pulpar vital radicular remanente, restauración del diente tratado, reacción pulpar, niveles de éxito clínico y radiográfico, complicaciones y otros, 8) número de autores, 9) número de citaciones recibidas por cada estudio, y por último 10) número de referencias bibliográficas empleadas en cada artículo.

El número de citas recibidas por estudio se obtuvo de la WoS.

Para la organización y tratamiento de los datos y para la elaboración de gráficos se utilizó el programa Excel del paquete de software Microsoft Office ${ }^{\circledR}$ versión 16.17. para macOS High Sierra versión 10.13.6. 
Los datos se mostraron con el uso de estadísticas descriptivas.

\section{Resultados}

El análisis de la distribución cronológica de los 204 artículos seleccionados mostró una tendencia creciente de la producción en el intervalo de tiempo estudiado. El punto cronológico de aceleración fue el año 2000, multiplicándose por 38 la producción de la década de los 90 en los primeros 10 años del siglo XXI. Entre 2010 y 2017 se publicaron más artículos $(n=111)$ que en los 50 años previos $(n=93)$. La tabla 1 muestra el número de artículos publicados sobre pulpotomía en DP y su distribución por décadas.

Los artículos seleccionados se publicaron en un total de 39 revistas presentadas en la tabla 2, junto con la distribución de los trabajos por décadas, observándose en el tiempo un aumento progresivo del número de revistas y del número de artículos publicados por revista. Al analizar el número de revistas por década se observó que del año 1960 al 2000 este osciló entre 2 y 5 , aumentando a partir del año 2000 , identificándose 33 revistas entre los años 2000 y 2017.

Del número total de revistas, 10 estaban especializadas en odontología pediátrica y las 29 restantes fueron de odontología general, de medicina o de otras áreas biosanitarias. Treinta y dos revistas pertenecían a la categoría "Dentistry, Oral Surgery and Medicine" del Journal Citation Reports (JCR), las restantes estuvieron incluidas en 5 categorías diferentes (surgery, clinical neurology, general and internal medicine, biomedical engineering/surgery and microscopy) y sólo una no estaba incluida en el JCR.

El número total de autores firmantes fue de 613 . Un solo autor $(0,16 \%$ de todos los

Tabla 1. Número de artículos publicados sobre pulpotomía en DP, promedio de autores firmantes, de citas recibidas y de referencias bibliografías empleadas por artículo desde 1960 al 2017 en conjunto y por décadas.

\begin{tabular}{lcccc} 
Década & $\begin{array}{c}\text { Número de } \\
\text { artículos }\end{array}$ & $\begin{array}{c}\text { Autores firmantes } \\
\text { por artículo }(\dot{x})\end{array}$ & $\begin{array}{c}\text { Citas recibidas } \\
\text { por artículo }(\dot{x})\end{array}$ & $\begin{array}{c}\text { Referencias bibliográficas } \\
\text { por artículo }(\dot{x})\end{array}$ \\
\hline $1960-69$ & 5 & 2 & 18,6 & 23,2 \\
\hline $1970-79$ & 4 & 2,5 & 5,75 & 21 \\
\hline $1980-89$ & 16 & 2,31 & 15,25 & 21,93 \\
\hline $1990-99$ & 14 & 2,64 & 21,57 & 29,57 \\
\hline $2000-09$ & 54 & 3,35 & 27,35 & 38,05 \\
\hline $2010-17$ & 111 & 4,35 & 7,93 & 33,93 \\
\hline Promedio & 34 & 2,858 & 16,07 & 27,94 \\
$1960-2017$ & & & &
\end{tabular}

xं: media aritmética 
Tabla 2. Revistas que publicaron artículos sobre pulpotomía en DP entre 1960 y 2017 y su producción por décadas.

\begin{tabular}{|c|c|c|c|c|c|c|c|}
\hline Revista & 1960-1969 & 1970-1979 & 1980-1989 & 1990-1999 & 2000-2009 & 2010-2017 & 1960-2017 \\
\hline Chin J Dent Res & & & & & & 1 & 1 \\
\hline Clin Oral Invest & & & & & & 1 & 1 \\
\hline Curr Opin Dent & & & & 1 & & & 1 \\
\hline Cochrane Database Syst Rev & & & & & 1 & & 1 \\
\hline Contemp Clin Dent & & & & & & 3 & 3 \\
\hline Eur Arch Paediatr Dent & & & & & 4 & 10 & 14 \\
\hline Eur J Dent & & & & & & 3 & 3 \\
\hline Eur J of Paediatr Dent & & & & & 5 & 4 & 9 \\
\hline Indian J Dent Res & & & & & 1 & 2 & 3 \\
\hline Int Endod J & & & & & 4 & 4 & 8 \\
\hline Int J Clin Pediatr Dent & & & & & 1 & 10 & 11 \\
\hline Int J Paediatr Dent & & & & 1 & 8 & 2 & 11 \\
\hline Iran Endod J & & & & & & 5 & 5 \\
\hline J Am Dent Assoc & 1 & & & & & 1 & 2 \\
\hline J Clin Diagn Res & & & & & & 3 & 3 \\
\hline J Clin Pediatr Dent & & & & 5 & 7 & 8 & 20 \\
\hline$J$ Contemp Dent Pract & & & & & & 3 & 3 \\
\hline J Dent & & & & & & 1 & 1 \\
\hline J Dent Child & 3 & & 1 & 1 & 1 & & 6 \\
\hline J Dent Res & 1 & & & & & & 1 \\
\hline J Endod & & & 2 & & 3 & 5 & 10 \\
\hline J Evid Based Dent Pract & & & & & & 1 & 1 \\
\hline J Indian Soc Pedod Prev Dent & & & & & 2 & 5 & 7 \\
\hline J Int Ass Dent Child & & 1 & 1 & & & & 2 \\
\hline$J$ Int Oral Health & & & & & & 2 & 2 \\
\hline$J$ Int Soc Prev and Community Dent & & & & & & 1 & 1 \\
\hline J Investig Clin Dent & & & & & & 1 & 1 \\
\hline J Microsc & & & & & & 1 & 1 \\
\hline$J$ Oral Dis & & & & & & 1 & 1 \\
\hline$J$ Pedod & & 3 & 5 & & & & 8 \\
\hline Laser Ther & & & & & & 1 & 1 \\
\hline Lasers Med Sci & & & & & 1 & 1 & 2 \\
\hline Med Oral Patol Oral Cir Bucal & & & & & & 1 & 1 \\
\hline Niger J Clin Pract & & & & & & 2 & 2 \\
\hline Pain Res Manag & & & & & & 1 & 1 \\
\hline Pediatr Dent & & & 7 & 6 & 16 & 24 & 53 \\
\hline Photomed Laser Surg & & & & & & 1 & 1 \\
\hline Quintessence Int & & & & & & 1 & 1 \\
\hline Restor Dent Endod & & & & & & 1 & 1 \\
\hline Total general & 5 & 4 & 16 & 14 & 54 & 111 & 204 \\
\hline
\end{tabular}


autores) escribió 9 artículos, dos autores escribieron 7 cada uno, tres autores 5 , doce autores 3 , cincuenta y seis autores 2 y los restantes 534 autores (87,1\%) sólo 1. Los primeros autores firmantes de los trabajos seleccionados pertenecían a 172 instituciones: 138 (80,23\%) fueron universidades, 12 hospitales (6,97\%), 16 institutos o centros de investigación (9,30\%), 5 centros odontológicos (2,90\%) y un grupo de autores no vinculados a ninguna institución al que se ha llamado "consulta privada" como muestra el anexo 2. Este anexo también permite corroborar el aumento progresivo de la producción a lo largo de las décadas en términos porcentuales.
Antes del 2000, la mayoría de los artículos tenían uno o dos autores. La tabla 1 muestra cómo el número medio de autores por artículo aumentó progresivamente de 1960 al 2017, con una media de 2,85 autores firmantes por artículo durante los 57 años estudiados. Los artículos publicados de 1960 al 2000 fueron escritos por el 55,14\% del total de autores, porcentaje similar al del número de firmantes de los artículos publicados entre 2010 y 2017 (44,86\%).

Los trabajos seleccionados procedieron de 30 países diferentes, destacando la productividad de los Estados Unidos (EE.UU) y la India: 40 y 38 artículos respectivamente. La tabla 3 muestra la productividad por país y por década.

Tabla 3. Productividad de artículos sobre pulpotomía en DP por país y por decada desde 1960 a 2017.

\begin{tabular}{|c|c|c|c|c|c|c|c|}
\hline PAÍS & 1960-1969 & 1970-1979 & 1980-1989 & 1990-1999 & 2000-2009 & 2010-2017 & Total \\
\hline Arabia Saudita & & & & & 1 & 7 & 8 (3,92\%) \\
\hline Australia & & 1 & 1 & 1 & 3 & 1 & 7 (3,43\%) \\
\hline Bélgica & & & 1 & & & 4 & $5(2,45 \%)$ \\
\hline Brasil & & & & & 4 & 9 & $13(6,37 \%)$ \\
\hline Canadá & & & & & 3 & 5 & $8(3,92 \%)$ \\
\hline China & & & & & 1 & 1 & 2 (0,98\%) \\
\hline Colombia & & & & & & 1 & $1(0,49 \%)$ \\
\hline Corea del Sur & & & & & & 2 & $2(0,98 \%)$ \\
\hline Egipto & & & & & 2 & 2 & $4(1,96 \%)$ \\
\hline España & & & & 2 & 2 & 4 & $8(3,92 \%)$ \\
\hline EE.UU. & 5 & 2 & 8 & 4 & 10 & 11 & $40(19,61 \%)$ \\
\hline Francia & & & & & & 1 & $1(0,49 \%)$ \\
\hline Grecia & & & & & 1 & & $1(0,49 \%)$ \\
\hline India & & & 1 & 1 & 5 & 31 & $38(19,12 \%)$ \\
\hline Irán & & & & 1 & 6 & 11 & $18(8,82 \%)$ \\
\hline Israel & & & 2 & 3 & 4 & 1 & $10(4,90 \%)$ \\
\hline Italia & & & & & & 1 & $1(0,49 \%)$ \\
\hline Japón & & & 1 & & & & 1 (0,49\%) \\
\hline Kuwait & & & & & 2 & & $2(0,98 \%)$ \\
\hline Malta & & & & & & 1 & $1(0,49 \%)$ \\
\hline México & & & & & & 2 & $2(0,98 \%)$ \\
\hline Nigeria & & & & & & 1 & $1(0,49 \%)$ \\
\hline
\end{tabular}


Tabla 3. Productividad de artículos sobre pulpotomía en DP por país y por decada desde 1960 a 2017. (cont.)

\begin{tabular}{|c|c|c|c|c|c|c|c|}
\hline PAÍS & 1960-1969 & 1970-1979 & 1980-1989 & 1990-1999 & 2000-2009 & 2010-2017 & Total \\
\hline Reino Unido & & & & 1 & 5 & 1 & $7(3,43 \%)$ \\
\hline Serbia & & & & & 1 & & $1(0,49 \%)$ \\
\hline Sudáfrica & & & & & 1 & & $1(0,49 \%)$ \\
\hline Suecia & & 1 & & & & & $1(0,49 \%)$ \\
\hline Suiza & & & & & 1 & & $1(0,49 \%)$ \\
\hline Taiwán & & & & 1 & 1 & 1 & $3(1,47 \%)$ \\
\hline Tailandia & & & & & & 3 & $3(1,47 \%)$ \\
\hline Turquía & & & 2 & & 1 & 10 & $13(6,37 \%)$ \\
\hline Total & 5 & 4 & 16 & 14 & 54 & 111 & $204(100,00 \%)$ \\
\hline
\end{tabular}

El tema más investigado en los años estudiados fue el de los posibles materiales para tratar el tejido pulpar radicular vital remanente, con un total de 169 artículos. Nueve trabajos versaron sobre la terapia pulpar en DP en general tanto vital como necrótica, 7 sobre pulpotomía en DP en general, 5 sobre éxito clínico y radiográfico de la pulpotomía en DP, 5 sobre posibles complicaciones, 4 guías clínicas, 2 sobre la reacción pulpar del diente tratado, 2 sobre la restauración del diente pulpotomizado y 1 solo artículo fue clasificado en "otros".

La figura 2 recoge la productividad según el campo temático de los artículos seleccionados por décadas.

El tipo de estudio más realizado en el tiempo estudiado fue el EINA (50\%). La figura 3 recoge la distribución de la muestra según el tipo de estudio por décadas.

La tabla 1 muestra el aumento progresivo del número medio de citas recibidas por artículo a lo largo de las décadas estudiadas especialmente hasta 2010, con una media de 16,07 citas por artículo a lo largo de los 57 años analizados. Los artículos con

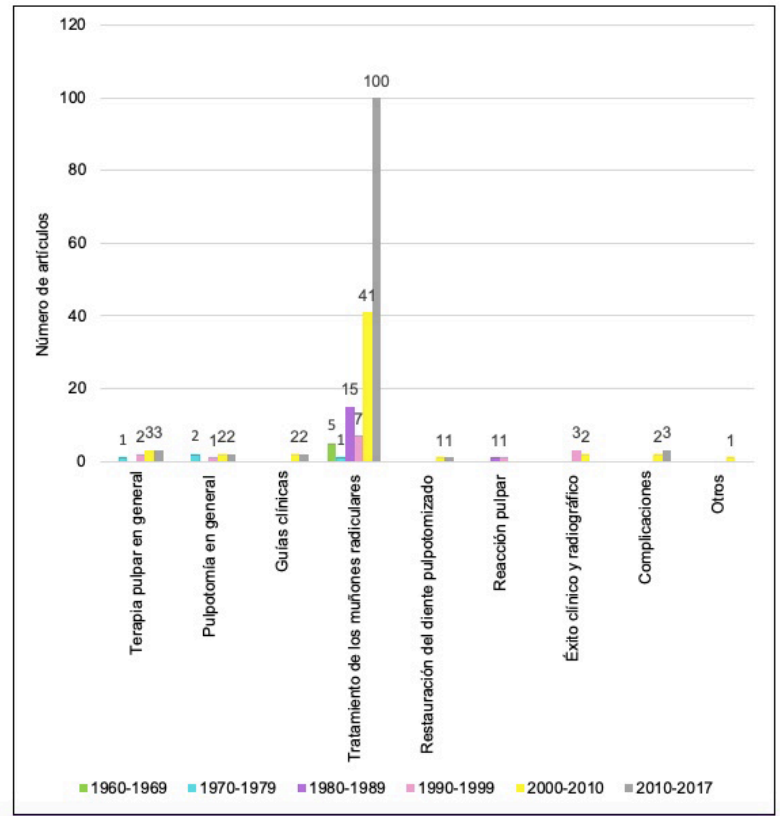

Figura 2. Productividad según campo temático de los artículos seleccionados sobre pulpotomía en DP por décadas.

menos citas no presentaron ninguna y el que más 120 . Solo 2 artículos presentaron 100 citas o más (anexo 3) también hubo un aumento de aproximadamente el $10 \%$ en el número medio de referencias bibliográficas utilizadas por artículo en los 57 años estudiados y una media en estos años de 27,94 referencias por artículo. 


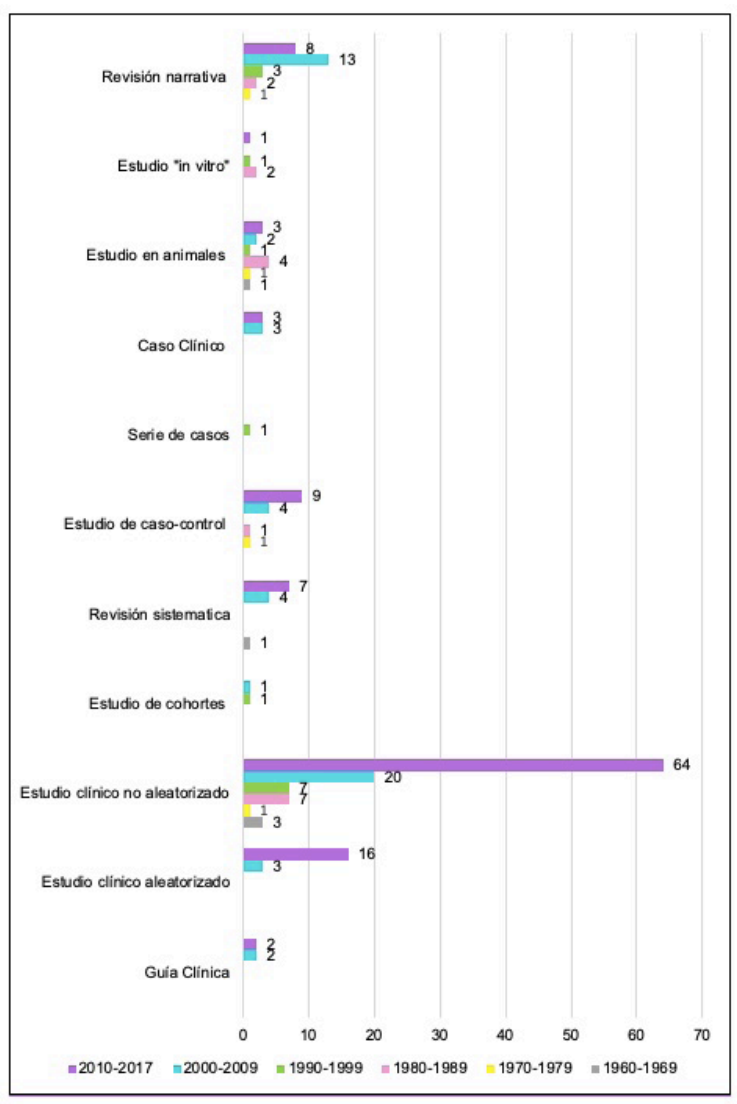

Figura 3. Clasificación de los artículos seleccionados según el tipo de estudio por décadas

\section{Discusión}

\section{Distribución cronológica de los documentos}

Para este análisis bibliométrico se seleccionaron 204 artículos publicados a lo largo de 57 años. Entre 1960 y 2017 hubo una tendencia creciente en la producción de artículos sobre pulpotomía en DP y una aceleración de la misma a partir del año 2000. Esta tendencia también fue observada por Haddad en Brasil ${ }^{17}$ o por Dhillon y cols. ${ }^{13}$ en la India. Estos últimos informaron de un aumento en la tendencia de las publicaciones desde 2005, con un máximo en 2010 que siguió aumentando hasta 2012. Este crecimiento significativo se atribuyó al aumento del número de escuelas de odontología y de estudios de postgrado en odontología pediátrica. Otra posible causa atribuida fue que, uno de los requisitos que deben cumplir los profesores universitarios para avanzar en su carrera docente es la publicación de artículos en revistas de impacto y no podemos olvidar que en nuestro estudio el $80,23 \%$ de las instituciones a las que pertenecían los primeros autores de los trabajos seleccionados fueron universidades. Además, en el presente estudio la temática ha podido influir también en el incremento de artículos publicados, ya que sabemos que los temas con mayor crecimiento en su producción son aquellos que despiertan interés entre los profesionales por ser directamente aplicables a clínica y la realización de pulpotomías en dientes primarios es todavía un procedimiento casi cotidiano en las clínicas donde se atiende y trata a pacientes pediátricos. Yang y cols. ${ }^{14}$ refirieron en su estudio que desde 1989 a 1999 el porcentaje de crecimiento del número de artículos publicados sobre tratamiento pulpar en menores de 12 años presentes en Medline fue del $9 \%$. Sin embargo en nuestros resultados la única década en la que se percibió un freno en la tendencia de crecimiento fue la década de los 90.

Jayarathe y cols. ${ }^{11}$ atribuyeron también el significativo aumento de artículos publicados a la generalización del uso de internet que logra una difusión más rápida y amplia del conocimiento.

\section{Productividad por revistas}

En la bibliografía revisada algunos estudios como el de Kramer y cols. ${ }^{16}$ o el de Poletto 
y cols. ${ }^{18}$ se referían sólo a la producción científica de una única revista. El estudio de Wilson y cols. ${ }^{19}$ seleccionó 168 artículos publicados en dos revistas: Pediatric Dentistry y Journal of Dentistry for Children las mismas dos analizadas por Naimar. ${ }^{20}$ Jarayaman y cols. ${ }^{21}$ y Perazzo y cols. 16 identificaron 5 revistas en sus respectivos estudios, todas ellas especializadas en odontopediatría. Aura y cols. ${ }^{12}$ analizaron 8 revistas sobre temática ortodóncica: The European Journal of Orthodontics, American Journal of Orthodontics and Dentofacial Orthopedics, the Angle Orthodontist, Korean Journal of Orthodontics, Orthodontics \& Craniofacial Research, Journal of Orofacial Orthopedics, Australasian Orthodontic Journal, and Seminars in Orthodontics.

El presente estudio estuvo centrado en la temática de los artículos seleccionados y no en el análisis de determinadas revistas científicas por lo que el número de estas identificado fue más alto que en trabajos previos: 39.

\section{Productividad por autores}

Se observó una tendencia polarizada en la productividad de los autores, es decir, muy pocos investigadores con un alto número de publicaciones y muchos con pocos trabajos. El uso de este indicador no se encontró en ningún estudio anterior, sin embargo, Susarla y cols. ${ }^{22}$ observaron que en general cuanto mayor es el rango académico de los autores, mayor es su productividad científica, ya que existe una fuerte correlación entre la eminencia de un científico y su productividad. ${ }^{23}$

\section{Productividad por países}

En el análisis del origen geográfico de los artículos, se identificaron 30 países, destacando la productividad de EE.UU. con 40 e India con 38 artículos. Ambos países aún con número similar de trabajos publicados expresan dos situaciones diferentes: EE.UU. aunque aumentó el número de publicaciones sobre pulpotomia en DP desde el año 2000 tiene artículos desde 1960. India, sin embargo, comenzó a publicar al respecto en 1980 , con el $94,73 \%$ de su producción entre los años 2000 y 2017. Por tanto, mientras que EE.UU. es un centro de investigación clásico, India es un país emergente. Kramer y cols. ${ }^{15}$ recogieron artículos sobre traumatología en DP de 29 países entre 2000 y 2014 y señalaron que hace 20 años gran parte de la producción científica era de investigadores europeos o norteamericanos, mientras que actualmente países emergentes como Brasil, Turquía, India, China, Corea del Sur, Hong Kong, Tailandia, Jordania e Irán están ganando protagonismo al respecto. El aumento de su número de publicaciones y su importante nivel de especialización ponen de manifiesto los esfuerzos que están realizando para aumentar su presencia en la escena científica internacional. ${ }^{24}$

\section{Productividad por tipo de artículo}

Se observó un predominio de EINAs, que fueron la mitad de todos los artículos seleccionados. Este resultado difiere mucho de los obtenidos por Kramer y cols. ${ }^{15}$, Poletto y cols. ${ }^{18}$ o Naimar y cols. ${ }^{25}$ en cuyos trabajos el porcentaje de EINAs se mantuvo entre 0,7 y $3 \%$. El segundo tipo de estudio más frecuente que encontramos 
fue la revisión de la literatura (13,24\%), una cifra similar a la observada por Kramer y cols. ${ }^{15}$ Estas revisiones narrativas pueden ayudar en la síntesis de un tema, incluyendo información actualizada que guía al lector en la toma de decisiones clínicas, pero no ayudan a producir evidencia, sino que reflejan opiniones, filosofías de trabajo o compilaciones de información sin ningún otro análisis. ${ }^{26}$

Los ECAs constituyeron el $9,31 \%$ de la muestra, un porcentaje muy alto comparado con el obtenido por Naimar y cols. ${ }^{20}(6 \%)$ o Poletto y cols..$^{18}(2,4 \%)$. Perazzo y cols. ${ }^{16}$ encontraron entre los 100 artículos más citados en odontopediatría solo 4 ECAs.

Entre ECAs y EINAs aproximadamente el $60 \%$ de todos los artículos seleccionados fueron estudios clínicos. Con el creciente énfasis en la toma de decisiones clínicas basadas en la evidencia, se está prestando cada vez más atención a los estudios de alta calidad, preferiblemente a las revisiones sistemáticas de los estudios clínicos y los estudios de cohorte y esta tendencia se observó en los resultados del presente estudio pues más de la mitad de los EINAs fueron realizados entre 2000 y 2017 y los ECAs son todos del siglo XXI, al igual que las revisiones sistemáticas. Estos diseños de estudio son los que tienen capacidad de producir evidencia clinicamente aplicable. ${ }^{15}$

\section{Productividad por contenido temático}

La temática de los artículos seleccionados en este estudio reveló un gran interés por el tratamiento de la pulpa radicular remanente. El $82,84 \%$ de los estudios fueron sobre este tema probando diferentes materiales y fármacos. Poletto y cols. ${ }^{18}$ encontraron que el segundo tema más frecuente en los artículos publicados en la principal revista brasileña de odontología pediátrica fue la odontología restauradora y los materiales dentales empleados en ella. Naimar y cols. ${ }^{20}$ observaron una disminución en el número de artículos sobre orientación del comportamiento, traumatología dental, crecimiento y desarrollo dental, ortodoncia y terapia pulpar en general, no ocurriendo lo mismo con los relacionados con la restauración de los dientes y los materiales dentales. Jayaraman y cols. ${ }^{21}$ encontraron que los temas más tratados en las revisiones sistemáticas que evaluaron fueron: la prevención, los procedimientos restauradores, los procedimientos endodónticos pediátricos y la orientación conductual.

\section{Número de autores por artículo}

Antes del año 2000, los artículos tenían uno o dos autores, posteriormente esta cifra fue en aumento hasta encontrar en el año 2017 el artículo con el mayor número de firmantes: $12^{27}$. Dhillon y cols. ${ }^{13}$ observaron que el número de autores en su estudio se mantuvo en un rango entre 1 y 8 con un promedio de 3,26 entre 2000 y 2012 , número similar al obtenido en nuestro estudio en esos años: 3,85 autores/artículo. Jayaraman y cols. ${ }^{21}$ realizaron una revisión sistémica para evaluar la calidad crítica de las revisiones publicadas en revistas dentales pediátricas entre 2010 y 2017. Observaron que el número de autores firmantes varió entre 2 y 17 con una media de 5,66 autores/artículo, cifra superior a la obtenida en el presente estudio durante el mismo periodo de tiempo: 4,35 autores/ artículo. Es probable que este aumento del número de firmantes esté relacionado con 
dos características de la investigación actual: el trabajo por equipos de investigación y la relación existente entre publicación y la progresión de los investigadores en el rango académico universitario. ${ }^{21,23}$

\section{Número de citas recibidas por artículo}

Susarla y cols. ${ }^{22}$ en su estudio observaron un número promedio de citas recibidas de 218,4 con un número máximo de citas recibidas por artículo de 42 , todas ellas pertenecientes al trabajo total publicado por los 267 profesores a tiempo completo de los equipos de odontología pediátrica de 60 programas de especialización en los EE.UU. y Canadá. Sin embargo, los autores no indicaron el número total de publicaciones, ni las fechas, lo que dificulta la comparación de resultados. Jayarathe y cols. ${ }^{11}$ evaluaron las tendencias relacionadas con el rendimiento académico de las revistas dentales y observaron que el número promedio de citas obtenidas por estas revistas se duplicó pasando de 97,08 en 2003 a 233 en 2012, con un promedio de 165,16 citas para esos 10 años. En el presente trabajo no analizamos las citas por autor o por revista sino por artículo, por lo que los números obtenidos son mucho menores: 27,35 citas/artículo entre 2000 y 2009. Habitualmente se consideran artículos clásicos aquellos que han recibido 400 citas o más. Sin embargo en algunos campos con un número menor de investigadores como la odontopediatría 100 citas podría ser una cantidad apropiada para definir un artículo como clásico. ${ }^{16} \mathrm{En}$ este estudio sólo encontramos 2 artículos que podrían considerarse clásicos, el de Agamy y cols. ${ }^{28}$ (EE.UU, 2004) y el de Holan y cols. ${ }^{29}$ (Israel, 2005). Las fechas de ambos trabajos confirman un hallazgo del análisis bibliométrico realizado por Perazzo y cols. ${ }^{16}$ y es que los documentos más citados en odontopediatría se publicaron mayoritariamente en las dos primeras décadas del siglo XXI. Estos autores afirmaron que aunque un documento antiguo por tiempo de vida debería acumular un mayor número de citas, la evolución de la investigación genera el aumento de citas de estudios más recientes. Jayarathe y cols. ${ }^{11}$, mencionaron un aspecto importante y es que el número de citas por si mismo no es un reflejo exacto del uso de una revista o un artículo. Los investigadores pueden leer un artículo y discutirlo entre ellos, pero no citarlo. En este momento, todavía no disponemos de indicadores que recojan el uso de artículos y revistas entre sus lectores.

\section{Limitaciones}

Este trabajo presenta una serie de limitaciones que es importante tener en mente a la hora de considerar sus resultados. Los artículos seleccionados para llevar a cabo este estudio debían estar disponibles a texto completo en versión electrónica, lo que puede haber supuesto un sesgo de publicación. Es decir, puede haber algunos artículos publicados, especialmente entre los años sesenta y ochenta del siglo pasado, de los que no disponemos de una versión electrónica a texto completo. Esto podría haber infravalorado los datos correspondientes a esas dos décadas estudiadas.

Además el establecimiento de los grupos para clasificar los artículos en función del tipo de estudio, de su contenido temático y de la institución de origen conllevó una carga de subjetividad. Para minimizarla se garantizó: 1) que todos los trabajos quedaran incluidos dentro de las categorizaciones establecidas y 2) el trabajo independiente de dos 
investigadoras que posteriormente llegaron a consenso sobre el establecimiento de los grupos y la clasificación de los artículos en ellos y el de una tercera investigadora para subsanar las diferencias surgidas.

Por último es importante tener en cuenta que los artículos seleccionados en este trabajo fueron publicados entre los años 1960 y 2017 . Esta acotación temporal hace que la información: 1) novedosa ya que se trata del primer análisis bibliométrico realizado sobre uno de los temas sobre los que más se ha publicado en el área odontopediatríca e 2) interesante puesto que recoge el trabajo realizado al respecto a nivel mundial a lo largo de 57 años; pueda parecer desactualizada. De cara a futuros trabajos sería de mucho interés comprobar si el cambio de paradigma que estamos viviendo en relación al manejo de las lesiones profundas de caries que pone el enfásis en mantener la vitalidad pulpar mediante la detención del proceso carioso, la promoción de la esclerosis dentinaria, la estimulación de dentina terciaria y la curación del complejo dentino pulpar se ha visto reflejada en la producción de literatura científica sobre pulpotomía en DP en los últimos 4 años y de que manera lo ha hecho.

\section{Conflicto de intereses:}

Todas las autoras declaran no tener ningún conflicto de intereses en la realización de este estudio.

\section{Agradecimientos:}

Las autoras agradecen a D. Isaac Hernández por su asesoría en este análisis bibliométrico.

\section{Conclusiones:}

1. El número de artículos publicados sobre pulpotomía en dentición primaria aumentó progresivamente entre 1960 y 2017, especialmente a partir del año 2000. Los trabajos se publicaron principalmente en revistas no especializadas en odontopediatría y la temática de mayor interés fue el tratamiento de la pulpa radicular vital remanente buscando cada vez más la realización de estudios capaces de producir evidencia científica aplicable.

2. En la investigación sobre pulpotomía en dentición primaria han ganado protagonismo los países emergentes. Los estudios se realizaron principalmente en universidades ya que publicar en revistas de impacto es requisito para progresar en la carrera docente. Esto ha generado el aumento del número de firmantes y de la citación de estudios más recientes.

\section{Referencias bibliográficas}

1. Fuks AB. Current concepts in vital primary pulp therapy. Eur J Paediatr Dent. 2002;3(3): 115-20.

2. Markovic D, Zivojinovic V, Vucetic M. Evaluation of three pulpotomy medicaments in primary teeth. Eur J Paediatr Dent. 2005; 6(3):133- 8.

3. Lourenço N, Marques NC, Fernandes AP, Hungaro Duarte MA, Abdo RC, Machado MA et al. Clinical and radiographic evaluation of Portland cement added to radiopacifying agents in primary molar pulpotomies. Eur Arch Paediatr Dent. 2015;16(5): 377-82.

4. González B, Moreno L, Morillo F, Bordons M. Bibliometric indicators for the analysis of the research performance of a multidisciplinary institution: the CSIC. Rev Esp Doc Cient. 2012; 35(1): 9-37. 
5. Davila M, Guzman R, Macareno H, Piñeres D, De la Rosa D, Caballero C. Bibliometrics: concepts and utility to study and medical training. Salud Uninorte. 2009; 25(2): 319-30.

6. Sanz E, Martín C. Técnicas bibliométricas aplicadas a los estudios de usuarios. Rev Gen Inf y Doc.1997;7(2):41-68.

7. Hood W, Wilson C. The literature of bibliometrics, scientometrics, and informetrics. Scientometrics. 2001;52(2): 291-314.

8. Belter C. Bibliometric indicators: opportunities and limits. J Med Lib Assoc. 2015;103(4): 219- 21.

9. Crespo J, Li Y, Ruiz J. The measurement of the effect on citation inequality of differences in citation practices across scientific fields. PLoS ONE. 2013; 8(3):1-9.

10. Pérez N. La bibliografía, bibliometría y las ciencias afines. ACIMED. 2002;10(3):1-2.

11. Jayarathe YSN, Zwahlen RA. The evolution of dental journals from 2003 to 2012: a bibliometric analisis. PLoS One. 2015; 10(3):1-10.

12. Aura-Tormos JI, García-Sanz V, Estrela F, Bellot-Arcís C, Paredes-Gallardo V. Current trends in orthodontic journals listed in Journal Citation Reports. A bibliometric study. Am J Orthod Dentofacial Orthop. 2019; 156(5): 663-74.

13. Dhillon J, Gill N. Contribution of Indian pediatric dentists to scientific literature during 2002-2012: a bibliometric analysis. Acta Inform Med. 2014; 22(3):199-202.

14. Yang S, Needleman R. A bibliometric analysis of the pediatric dental literature in MEDLINE. Pediatr Dent. 2001;23(5): 415-8.

15. Kramer PF, Onetto J, Flores MT, Borges TS, Faldens CA. Traumatic dental injuries in the primary dentition: a 15-year bibliometric analysis of dental traumatology. Dent Traumatol. 2016; 32(5): 341-6.

16. Perazzo MF, Otoni ALC, Costa MS, Granville-Granville AF, Paiva SM, Martins Jr. PA. The top 100 most-cited papers in paediatric dentistry journals: a bibliometric analysis. Int J Paediatr Dent. 2019; 29(2):692-711

17. Haddad AE. Brazilian oral research: combining scientific excellence and social impact. Braz Oral Res. 2008; 22(3):195- 6.

18. Poletto V, Faraco I. Bibliometric study of articles published in a Brazilian journal of pediatric dentistry. Braz Oral Res. 2010;24(1): 83-8.

19. Wilson S, Cody WE. An analysis of behavior management papers published in the pediatric dental. Pediatric Dent. 2005;27(4):331- 8.

20. Naimar SMH. Profile of pediatric dental literature: Thirty-year time trend (1969-1998). ASDC J Dent Child. 2001;68(6): 388-90.

21. Jayaraman J, Nagendrababu V, Pulikkotil SJ, Innes NP. Critical appraisal of methodological quality of systematic reviews and meta-analysis in paediatric dentistry journals. Int J Pae Dent. 2018; 28(6): 548-60.

22. Susarla HK, Dhar V, Karimbux N, Tinanoff N. Do standard bibliometric measures correlate with academic rank of full-time pediatric dentistry faculty members? J Dent Educ. 2017; 81(4):427-32.

23. Gonzalez J, Moya M, Mateos MA. Indicadores bibliométricos: características y limitaciones en el análisis de la actividad científica. An Esp Pediatr. 1997;47(3):235- 44.

24. Gil-Montoya JA, Navarrete-Cortes J, Pulgar R, Santa S, Moya-Anepón F. Word dental research production: an ISI database approach (1993-2003). Eur J Oral Sci. 2006;114(2): 102- 8.

25. Naimar SMH. Profile of Journal of Dentistry for Children and Pediatric Dentistry journal articles by evidence typology: thirthy-year time trends (1969-1998) and implications. Pediatr Dent. 2000; 22(6):475- 8.

26. 26. Oliveira GJ, Oliveira ES, Leles CR. Tipos de delineamiento de pesquisas de estudio publicado em periodicos odontológicos brasileiros. Rev Odonto Cência. 2007; 22(4):42-7.

27. Bakhitiar H, Nekoofar MH, Aminishakib P, Abedi F, Naghi Moosavi F, Esnaashari E, et al. Human pulp responses to partial pulpotomy treatment with TheraCal as compared with Biodentine and ProRoot MTA: a clinical trial. J Endod. 2017;43(11): 1786-91.

28. Agamy HA, Bakry NS, Mounir MM, Avery DR. Comparison of mineral trioxide aggregate and formocresol as pulp-capping agents in pulpotomized primary teeth. Pediatr Dent. 2004;26(4):302-9.

29. Holan G, Eidelman E, Fuks AB. Long-term evaluation of pulpotomy in primary molars using mineral trioxide aggregate or formocresol. Pediatr Dent. 2005;27(2):129-36.

Recibido: 01/05/21

Aceptado: 30/09/21

Correspondencia: Nathalia Reynoso, correo: nat.reynoso.ce@ceindo.ceu.es 
Anexo 1. Artículos seleccionados para ser parte de la muestra del estudio.

\section{Artículos 1960-1969}

- $\quad$ Law BD, Lewis TM. Formocresol pulpotomy in deciduous teeth. J Am Dent Assoc. 1964; 69(1):601-7.

- Spedding RH, Mitchell DF, McDonald RE. Formocresol and calcium hydroxide therapy. J Dent Res.1965; 44(5):102334.

- Beaver HA, Kopel HM, Sabes WR. The effect of zinc oxide-eugenol cement on a formocresolized pulp. J Dent Child.1966; 33(6):381-96.

- Redig DF. A comparison and evaluation of two formocresol pulpotomy technics utilizing "Buckley's" formocresol. J Dent Child. 1968; 35(1):22-30.

- Sayegh FS. Qualitative and quantitative evaluation of new dentin in pulp capped teeth. J Dent Child. 1968; 35(1):7-19.

\section{Artículos 1970-1979}

- Koch G, Nyborg H. Correlation between clinical and histological indications for pulpotomy of deciduous teeth. J Int Assoc Dent Child. 1970; 1(1):3-10.

- $\quad$ Ranly DM, Lazzari EP. The formocresol pulpotomy -the past, the present, and the future. J Pedod. 1978; 2(2):115-27.

- Wright FA, Widmer RP. Pulpal therapy in primary molar teeth: a retrospective study. J Pedod. 1979; 3(3):195-206.

- Halofsky M, Carrel R, Leifer C, Chialastri AJ. A comparison of formocresol and cresote-thymol pulpotomy materials in dogs. J Pedod. 1979; 3(2):129-41.

- Artículos 1980-1989

- Fuks AB, Bimstein E. Clinical evaluation of diluted formocresol pulpotomies in primary teeth of school children. Pediatr Dent. 1981; 3(4):321-4.

- Boeve C, Dermaut L. Formocresol pulpotomy in primary molars: a long-term radiographic evaluation. ASDC J Dent Child. 1982; 49(3):191-6.

- Fuks AB, Bimstein E, Bruchim A. Radiographic and histologic evaluation of the effect of two concentrations of formocresol on pulpotomized primary and young permanent teeth in monkeys. Pediatr Dent. 1983; 5(1):9-13.

- Ruemping DR, Morton TH Jr, Anderson MW. Electrosurgical pulpotomy in primates--a comparison with formocresol pulpotomy. Pediatr Dent. 1983; 5(1):14-8.

- Ranly DM. Glutaraldehyde purity and stability: implications for preparation, storage, and use as a pulpotomy agent. Pediatr Dent. 1984; 6(2):83-7.

- Lekka M, Hume WR, Wolinsky LE. Comparison between formaldehyde and glutaraldehyde diffusion through the root tissues of pulpotomy-treated teeth. J Pedod. 1984; 8(2):185-91.

- Verco PJ, Allen KR. Formocresol pulpotomies in primary teeth. J Int Assoc Dent Child. 1984; 15(1):51-5.

- Shoji S, Nakamura M, Horiuchi H. Histopathological changes in dental pulps irradiated by $\mathrm{CO} 2$ laser: a preliminary report on laser pulpotomy. J Endod. 1985; 11(9):379-84.

- Hicks MJ, Barr ES, Flaitz CM. Formocresol pulpotomies in primary molars: a radiographic study in a pediatric dentistry practice. J Pedod. 1986; 10(4):331-9.

- Shulman ER, Mclver FT, Burkes EJ Jr. Comparison of electrosurgery and formocresol as pulpotomy techniques in monkey primary teeth. Pediatr Dent. 1987; 9(3):189-94.

- Ranly DM, Garcia-Godoy F, Horn D. Time, concentration, and pH parameters for the use of glutaraldehyde as a pulpotomy agent: an in vitro study. Pediatr Dent.1987; 9(3):199-203.

- Garcia-Godoy F, Ranly DM. Clinical evaluation of pulpotomies with ZOE as the vehicle for glutaraldehyde. Pediatr Dent. 1987; 9(2):144-6.

- Sheller B, Morton TH Jr. Electrosurgical pulpotomy: a pilot study in humans. J Endod. 1987; 13(2):69-76.

- Prakash C, Chandra S, Jaiswal JN. Formocresol and glutaraldehyde pulpotomies in primary teeth. J Pedod. 1989; 13(4):314-22.

- Alacam A. Pulpal tissue changes following pulpotomies with formocresol, glutaraldehyde-calcium hydroxide, glutaraldehyde-zinc oxide eugenol pastes in primary teeth. J Pedod. 1989; 13(2):123-32.

- Alacam A. Long term effects of primary teeth pulpotomies with formocresol, glutaraldehyde-calcium hydroxide and glutaraldehyde-zinc oxide eugenol on succudaneous teeth. J Pedod. 1989; 13(4):307-13.

\section{Artículos 1990-1999}

- Fuks AB, Bimstein E, Guelmann M, Klein H. Assessment of a 2 percent buffered glutaraldehyde solution in pulpotomized primary teeth of schoolchildren. J Dent Child. 1990; 57(5):371-5.

- Fei AL, Udin RD, Johnson R. A clinical study of ferric sulfate as a pulpotomy agent in primary teeth. Pediatr Dent. 1991; 13(6):327-32.

- Gentner MR, Meyers IA, Symons AL. The floor of the pulp chamber following pulpotomy. J Clin Pediatr Dent. 1991; 16(1):20-4.

- $\quad$ Fuks AB, Eidelman E. Pulp therapy in the primary dentition. Curr Opin Dent.1991; 1(5):556-63. 
- $\quad$ Oztas N, Ulusu T, Oygür T, Cokpekin F. Comparison of electrosurgery and formocresol as pulpotomy techniques in dog primary teeth. J Clin Pediatr Dent. 1994;18(4):285-9.

- Ranly DM. Pulpotomy therapy in primary teeth: new modalities for old rationales. Pediatr Dent. 1994; 16(6):403-9.

- $\quad$ Roberts JF. Treatment of vital and non-vital primary molar teeth by one-stage formocresol pulpotomy: clinical success and effect upon age at exfoliation. Int J Paediatr Dent. 1996; 6(2):111-5.

- Fishman SA, Udin RD, Good DL, Rodef F. Success of electrofulguration pulpotomies covered by zinc oxide and eugenol or calcium hydroxide: a clinical study. Pediatr Dent. 1996; 18(5):385-90.

- Fuks AB, Holan G, Davis JM, Eidelman E. Ferric sulfate versus dilute formocresol in pulpotomized primary molars: long-term follow up. Pediatr Dent. 1997; 19(5):327-30.

- Prabhu NT, Munshi AK. Clinical, radiographic and histological observations of the radicular pulp following "feracrylum" pulpotomy. J Clin Pediatr Dent. 1997; 21(4):151-6.

- Cotes O, Boj JR, Canalda C, Carreras M. Pulpal tissue reaction to formocresol vs. ferric sulfate in pulpotomized rat teeth. J Clin Pediatr Dent. 1997; 21(2):247-53.

- $\quad$ Davina AB. A conservative approach to the pulpotomy in primary teeth. J Clin Pediatr Dent. 1998; 22(2):103-5.

- $\quad$ Elliott RD, Roberts MW, Burkes J, Phillips C. Evaluation of the carbon dioxide laser on vital human primary pulp tissue. Pediatr Dent. 1999; 21(6):327-31.

- $\quad$ Liu JF, Chen LR, Chao SY. Laser pulpotomy of primary teeth. Pediatr Dent. 1999; 21(2):128-9.

- Artículos 2000-2009

- $\quad$ Ibricevic H, al-Jame Q. Ferric sulfate as pulpotomy agent in primary teeth: twenty-month clinical follow-up. J Clin Pediatr Dent. 2000; 24(4):269-72.

- Waterhouse PJ, Nunn JH, Whitworth JM, Soames JV. Primary molar pulp therapy- histological evaluation of failure. Int J Paediatr Dent. 2000; 10(4):313-21.

- Papagiannoulis L. Clinical studies on ferric sulphate as a pulpotomy medicament in primary teeth. Eur J Paediatr Dent. 2002; 3(3):126-32.

- Dean JA, Mack RB, Fulkerson BT, Sanders BJ. Comparison of electrosurgical and formocresol pulpotomy procedures in children. Int J Paediatr Dent. 2002; 12(3):177-82.

- $\quad$ Fuks AB. Current concepts in vital primary pulp therapy. Eur J Paediatr Dent. 2002; 3(3):115-20.

- Cleaton-Jones P, Duggal M, Parak M, William S, Setze S. Ferric sulphate and formocresol pulpotomies in baboon primary molars: histological responses. Eur J Paediatr Dent. 2002; 3(3):121-5.

- Guelmann M, Fair J, Turner C, Courts FJ. The success of emergency pulpotomies in primary molars. Pediatr Dent. 2002; 24(3):217-20.

- $\quad$ Ibricevic H, Al-Jame Q. Ferric sulphate and formocresol in pulpotomy of primary molars: long term follow-up study. Eur J Paediatr Dent. 2003; 4(1):28-32.

- Hunter ML. Premature exfoliation of primary molars related to the use of formocresol in a multivisit pulpotomy technique: a case report. Int J Paediatr Dent. 2003; 13(5):362-4.

- Casas MJ, Layug MA, Kenny DJ, Johnston DH, Judd PL. Two-year outcomes of primary molar ferric sulfate pulpotomy and root canal therapy. Pediatr Dent. 2003; 25(2):97-102.

- $\quad$ Nadine G, Goel BR, Yeung CA, Glenny AM. Pulp therapy for extensive decay in primary teeth. Cochrane Database Syt Rev. 2003; 8(1):1-43.

- $\quad$ Kalaskar RR, Damle SG. Comparative evaluation of lyophilized freeze-dried platelet derived preparation with calcium hydroxide as pulpotomy agents in primary molars. J Indian Soc Pedod Prev Dent. 2004; 22(1):24-9.

- $\quad$ Agamy HA, Bakry NS, Mounir MM, Avery DR. Comparison of mineral trioxide aggregate and formocresol as pulpcapping agents in pulpotomized primary teeth. Pediatr Dent. 2004;26(4):302-9.

- $\quad$ Loh A, O'Hoy P, Tran X, Charles R, Hughes A, Kubo K, et al. Evidence-based assessment: evaluation of the formocresol versus ferric sulfate primary molar pulpotomy. Pediatr Dent. 2004;26(5):401-9.

- $\quad$ American Academy of Pediatric Dentistry. Guideline on pulp therapy for primary and young permanent teeth. Pediatr Dent. 2004;26(7):144-6.

- $\quad$ Saltzman B, Sigal M, Clokie C, Rukavina J, Titley K, Kulkarni GV. Assessment of a novel alternative to conventional formocresol-zinc oxide eugenol pulpotomy for the treatment of pulpally involved human primary teeth: diode lasermineral trioxide aggregate pulpotomy. Int J Paediatr Dent. 2005;15(6):437-47.

- Markovic D, Zivojinovic V, Vucetic M. Evaluation of three pulpotomy medicaments in primary teeth. Eur J Paediatr Dent. 2005;6(3):133-8.

- Holan G, Eidelman E, Fuks AB. Long-term evaluation of pulpotomy in primary molars using mineral trioxide aggregate or formocresol. Pediatr Dent. 2005;27(2):129-36.

- $\quad$ Naik S, Hegde AH. Mineral trioxide aggregate as a pulpotomy agent in primary molars: an in vivo study. J Indian Soc Pedod Prev Dent. 2005;23(1):13-6.

- $\quad$ Butani Y, Levy SM, Nowak AJ, Kanellis MJ, Heller K, Hartz AJ, et al. Overview of the evidence for clinical interventions in pediatric dentistry. Pediatr Dent. 2005;27(1):6-11.

- Guelmann M, Fair J, Bimstein E. Permanent versus temporary restorations after emergency pulpotomies in primary molars. Pediatr Dent. 2005;27(6):478-81. 
- Vargas KG, Packham B. Radiographic success of ferric sulfate and formocresol pulpotomies in relation to early exfoliation. Pediatr Dent. 2005;27(3):233-7.

- Farsi N, Alamoudi N, Balto K, Mushayt A. Success of mineral trioxide aggregate in pulpotomized primary molars. J Clin Pediatr Dent. 2005;29(4):307-11.

- Vargas KG, Packham B, Lowman D. Preliminary evaluation of sodium hypochlorite for pulpotomies in primary molars. Pediatr Dent. 2006;28(6):511-7.

- $\quad$ Liu JF. Effects of Nd:YAG laser pulpotomy on human primary molars. J Endod. 2006;32(5):404-7.

- Srinivasan V, Patchett CL, Waterhouse PJ. Is there life after Buckley's Formocresol? Part I - a narrative review of alternative interventions and materials. Int J Paediatr Dent. 2006;16(2):117-27.

- Patchett CL, Srinivasan V, Waterhouse PJ. Is there life after Buckley's formocresol? Part II - Development of a protocol for the management of extensive caries in the primary molar. Int J Paediatr Dent. 2006;16(3):199-206.

- Rodd HD, Waterhouse PJ, Fuks AB, Fayle SA, Moffat MA; British Society of Paediatric Dentistry. Pulp therapy for primary molars. Int J Paediatr Dent. 2006;16(1):15-23.

- Fuks A, Papagiannoulis L. Pulpotomy in primary teeth: review of the literature according to standardized assessment criteria. Eur Arch Paediatr Dent. 2006;1(2):64-72.

- Asián-González E, Pereira-Maestre M, Conde-Fernández D, Vilchez I, Segura-Egea JJ, Gutiérrez-Pérez JL. Dentigerous cyst associated with a formocresol pulpotomized deciduous molar. J Endod. 2007;33(4):488-92.

- Cortés O, Fernández J, Boj JR, Canalda C. Effect of formaldehyde on rat liver in doses used in pulpotomies. J Clin Pediatr Dent. 2007;31(3):179-82.

- Peng L, Ye L, Guo X, Tan H, Zhou X, Wang C et al. Evaluation of formocresol versus ferric sulphate primary molar pulpotomy: a systematic review and meta-analysis. Int Endod J. 2007;40(10):751-7.

- Sabbarini J, Mounir M, Dean J. Histological evaluation of enamel matrix derivative as a pulpotomy agent in primary teeth. Pediatr Dent. 2007;29(6):475-9.

- Moretti AB, Oliveira TM, Sakai VT, Santos CF, Machado MA, Abdo RC. Mineral trioxide aggregate pulpotomy of a primary second molar in a patient with agenesis of the permanent successor. Int Endod J. 2007;40(9):738-45.

- Aeinehchi M, Dadvand S, Fayazi S, Bayat-Movahed S. Randomized controlled trial of mineral trioxide aggregate and formocresol for pulpotomy in primary molar teeth. Int Endod J. 2007;40(4):261-7.

- Hingston EJ, Parmar S, Hunter ML. Vital pulpotomy in the primary dentition: attitudes and practices of community dental staff in Wales. Int J Paediatr Dent. 2007;17(3):186-91.

- Aminabadi NA, Farahani RM, Gajan EB. A clinical study of formocresol pulpotomy versus root canal therapy of vital primary incisors. J Clin Pediatr Dent. 2008;32(3):211-4.

- Sonmez D, Sari S, Cetinbaş T. A Comparison of four pulpotomy techniques in primary molars: a long-term follow-up. J Endod. 2008;34(8):950-5.

- Bahrololoomi Z, Moeintaghavi A, Emtiazi M, Hosseini G. Clinical and radiographic comparison of primary molars after formocresol and electrosurgical pulpotomy: a randomized clinical trial. Indian J Dent Res. 2008;19(3):219-23.

- Toomarian L, Fekrazad R, Sharifi D, Baghaei M, Rahimi H, Eslami B. Histopatological evaluation of pulpotomy with er:YsGG laser vs formocresol. Lasers Med Sci. 2008;23(4):443-50.

- Coll JA. Indirect pulp capping and primary teeth: is the primary tooth pulpotomy out of date? Pediatr Dent. 2008;30(3):230-6.

- Milnes AR. Is formocresol obsolete? A fresh look at the evidence concerning safety issues. Pediatr Dent. 2008;30(3):23746.

- Zurn D, Seale NS. Light-cured calcium hydroxide vs formocresol in human primary molar pulpotomies: a randomized controlled trial. Pediatr Dent. 2008;30(1):34-41.

- Ng FK, Messer LB. Mineral trioxide aggregate as a pulpotomy medicament: a narrative review. Eur Arch Paediatr Dent. 2008;9(1):4-11.

- Ng FK, Messer LB. Mineral trioxide aggregate as a pulpotomy medicament: an evidence-based assessment. Eur Arch Paediatr Dent. 2008;9(2):58-73.

- Moretti AB. The effectiveness of mineral trioxide aggregate, calcium hydroxide and formocresol for pulpotomies in primary teeth. Int Endod J. 2008;41(7):547-55.

- Fuks A. Vital pulp therapy with new materials for primary teeth: new directions and treatment perspectives. Pediatr Dent. 2008;30(3):211-9.

- Adlakha VK, Chandna P, Joshi J, Thomas A, Singh N. A comparative evaluation of hydroxyapatite crystals and glutaraldehyde as agents for pulpotomy in deciduous molars. Int J Clin Pediatr Dent. 2009;2(1):13-22.

- Chin JR, Westerman AE, Palenik CJ, Eckert SG. Contamination of handpieces during pulpotomy therapy on primary teeth. Pediatr Dent. 2009;31(1):71-5.

- Ferreira DC, Brito DG, Cavalcanti BN. Cytokine production from human primary teeth pulp fibroblasts stimulated by different pulpotomy agents. J Dent Child. 2009;76(3):194-8.

- De Menezes JV, Takamori ER, Bijella MF, Granjeiro JM. In vitro toxicity of MTA compared with other primary teeth pulpotomy agents. J Clin Pediatr Dent. 2009;33(3):217-21.

- $\quad$ Rao A, Rao A, Shenoy R. Mineral trioxide aggregate--a review. J Clin Pediatr Dent. 2009;34(1):1-7. 
- $\quad$ Subramaniam P, Konde S, Mathew S, Sugnani S. Mineral trioxide aggregate as pulp capping agent for primary teeth pulpotomy: 2 year follow up study. J Clin Pediatr Dent. 2009;33(4):311-4.

- $\quad$ Steffen R, Waes H. Understanding mineral trioxide aggregate/Portland-cement: a review of literature and background factors. Eur Arch Paediatr Dent. 2009;10(2):93-7.

- $\quad$ Artículos 2010-2017

- $\quad$ Gupta N, Bhat M, Devi P, Girish. Aloe-Vera: A nature's gift to children. Int J Clin Pediatr Dent. 2010;3(2):87-92.

- Hegde R, Battepati PM. Clinical applications of mineral trioxide aggregate: report of four cases. Int J Clin Pediatr Dent. 2010;3(1):43-50.

- Zealand CM, Briskie DM, Botero TM, Boynton JR, Hu JC. Comparing gray mineral trioxide aggregate and diluted formocresol in pulpotomized human primary molars. Pediatr Dent. 2010;32(5):393-9.

- $\quad$ Ansari G, Ranjpour M. Mineral trioxide aggregate and formocresol pulpotomy of primary teeth: a 2-year follow-up. Int Endod J. 2010;43(5):413-8.

- $\quad$ Doyle TL, Casas MJ, Kenny DJ, Judd PL. Mineral trioxide aggregate produces superior outcomes in vital primary molar pulpotomy. Pediatr Dent. 2010;32(1):41-7.

- $\quad$ Simancas-Pallares MA, Díaz-Caballero AJ, Luna-Ricardo LM. Mineral trioxide aggregate in primary teeth pulpotomy. A systematic literature review. Med Oral Patol Oral Cir Bucal. 2010;15(6):942-6.

- $\quad$ Kurji ZA, Sigal MJ, Andrews P, Titley K. A retrospective study of a modified 1-minute formocresol pulpotomy technique part 2: effect on exfoliation times and successors. Pediatr Dent. 2011;33(2):139-43.

- Kurji ZA, Sigal MJ, Andrews P, Titley K. A retrospective study of a modified 1-minute formocresol pulpotomy technique part 1: clinical and radiographic findings. Pediatr Dent. 2011;33(2):131-8.

- Gisoure EF. Comparison of three pulpotomy agents in primary molars: a randomised clinical trial. Iran Endod J. 2011;6(1):11-4.

- Guelmann M, Shapira J, Silva DR, Fuks AB. Esthetic restorative options for pulpotomized primary molars: a review of literature. J Clin Pediatr Dent. 2011;36(2):123-6.

- $\quad$ Liu H, Zhou Q, Qin M. Mineral trioxide aggregate versus calcium hydroxide for pulpotomy in primary molars. Chin J Dent Res. 2011;14(2):121-5.

- $\quad$ Boj JR, Poirier C, Hernandez M, Espassa E, Espanya A. Case series: laser treatments for soft tissue problems in children. Eur Arch Paediatr Dent. 2011;12(2):113-7.

- Nematollahi H, Sahebnasagh M, Parisay I. Comparison of electrosurgical pulpotomy with zinc oxide eugenol or zinc polycarboxylate cements sub-base. J Clin Pediatr Dent. 2011;36(2):133-7.

- $\quad$ Lima RV, Esmeraldo MR, de Carvalho MG, de Oliveira PT, de Carvalho RA, da Silva FL Jr, de Brito Costa EM. Pulp repair after pulpotomy using different pulp capping agents: a comparative histologic analysis. Pediatr Dent. 2011;33(1):14-8.

- Malekafzali B, Shekarchi F, Asgary S. Treatment outcomes of pulpotomy in primary molars using two endodontic biomaterials. A 2-year randomised clinical trial. Eur J Paediatr Dent. 2011;12(3):189-93.

- Srinivasan D, Jayanthi M. Comparative evaluation of formocresol and mineral trioxide aggregate as pulpotomy agents in deciduous teeth. Indian J Dent Res. 2011;22(3):385-90.

- $\quad$ Vostatek SF, Kanellis MJ, Weber-Gasparoni K, Gregorsok RL. Sodium hypochlorite pulpotomies in primary teeth: a retrospective assessment. Pediatr Dent. 2011;33(4):327-32.

- Erdem AP, Guven Y, Balli B, Ilhan B, Sepet E, Ulukapi I et al. Success rates of mineral trioxide aggregate, ferric sulfate, and formocresol pulpotomies: a 24-month study. Pediatr Dent. 2011;33(2):165-70.

- $\quad$ Ratnakumari N, Thomas B. A Histopathological comparison of pulpal response to Chitra-CPC and formocresol used as pulpotomy agents in primary teeth: A clinical trial. Int J Clin Pediatr Dent. 2012;5(1):6-13.

- Haghgoo R, Abbasi F. A histopathological comparison of pulpotomy with sodium hypochlorite and formocresol. Iran Endod J. 2012;7(2):60-2.

- $\quad$ Shayegan A, Jurysta C, Atash R, Petein M, Abbeele AV. Biodentine used as a pulp-capping agent in primary pig teeth. Pediatr Dent. 2012;34(7):202-8.

- $\quad$ Frenkel G, Kaufman A, Ashkenazi M. Clinical and radiographic outcomes of pulpotomized primary molars treated with white or gray mineral trioxide aggregate and ferric sulfate--long-term follow-up. J Clin Pediatr Dent. 2012;37(2):13741.

- $\quad$ Odabas M, Alacam A, Silleliuglu H, Deveci C. Clinical and radiographic success rates of mineral trioxide aggregate and ferric sulphate pulpotomies performed by dental students. Eur J Paediatr Dent. 2012;13(2):118-122.

- $\quad$ Airen P, Shigli A, Airen B. Comparative evaluation of formocresol and mineral trioxide aggregate in pulpotomized primary molars--2 year follow up. J Clin Pediatr Dent. 2012;37(2):143-7.

- $\quad$ Sushynski JM, Zealand CM, Botero TM, Boyton JR, Majewski RF, Shelburne CE et al. Comparison of gray mineral trioxide aggregate and diluted formocresol in pulpotomized primary molars: a 6- to 24-month observation. Pediatr Dent. 2012;34(5):120-8.

- Yaman E, Görken F, Pinar Erdem A, Sepet E, Aytepe Z. Effects of folk medicinal plant extract Ankaferd Blood Stopper(ß) in vital primary molar pulpotomy. Eur Arch Paediatr Dent. 2012;13(5):197-202.

- Omar OM, Khattab NM, Khater DS. Nigella sativa oil as a pulp medicament for pulpotomized teeth: a histopathological evaluation. J Clin Pediatr Dent. 2012;36(4):335-41. 
- Bowen JL, Mathu-Muju KR, Nash DA, Chance KB, Bush HM, Li HF. Pediatric and general dentists' attitudes toward pulp therapy for primary teeth. Pediatr Dent. 2012;34(4):210-5.

- Howley B, Seale NS, McWhorter AG, Kerins C, Boozer KB, Lindsey D. Pulpotomy versus pulpectomy for carious vital primary incisors: randomized controlled trial. Pediatr Dent. 2012;34(5):112-9.

- Trairatvorakul C, Koothiratrakarn A. Calcium hydroxide partial pulpotomy is an alternative to formocresol pulpotomy based on a 3-year randomized trial. Int J Paediatr Dent. 2012;22(5):382-9.

- De Coster P, Rajasekharan S, Martens L. Laser-assisted pulpotomy in primary teeth: a systematic review. Pediatr Dent. 2013; 23(6):389-99.

- Ruby JD, Cox CF, Mitchell SC, Makhija S, Chompu-Inwai P, Jackson J. A randomized study of sodium hypochlorite versus formocresol pulpotomy in primary molar teeth. Int J Paediatr Dent. 2013;23(2):145-52.

- Bijimole J, Ratnakumari N, Mohanty M, Varma HK, Komath M. Calcium phosphate cement as an alternative for formocresol in primary teeth pulpotomies. Indian J Dent Res. 2013;24(4):522-30.

- Oliveira TM. Clinical, radiographic and histologic analysis of the effects of pulp capping materials used in pulpotomies of human primary teeth. Eur Arch Paediatr Dent. 2013;14(2):65-71.

- Fernández CC, Martínez SS, Jimeno FG, Lorente-Rodríguez AI, Mercadé M. Clinical and radiographic outcomes of the use of four dressing materials in pulpotomized primary molars: a randomized clinical trial with 2-year follow-up. Int J Paediatr Dent. 2013;23(6):400-7.

- Mettlach SE, Zealand CM, Botero TM, Boynton JR, Majewski RF, Hu JC. Comparison of mineral trioxide aggregate and diluted formocresol in pulpotomized human primary molars: 42-month follow-up and survival analysis. Pediatr Dent. 2013;35(3):87-94.

- Mehrdad L, Malekafzali B, Shekarchi F, Safi Y, Asgary S. Histological and CBCT evaluation of a pulpotomised primary molar using calcium enriched mixture cement. Eur Arch Paediatr Dent. 2013;14(3):191-4.

- Anthonappa P, King N, Martens L. Is there sufficient evidence to support the long-term efficacy of mineral trioxide aggregate (MTA) for endodontic therapy in primary teeth? Int Endod J. 2013;46(3):198-204.

- Subay RK, Ilhan B, Ulukapi H. Mineral trioxide aggregate as a pulpotomy agent in immature teeth: Long-term case report. Eur J Dent. 2013;7(1):133-8.

- Al-Mutairi MA, Bawazir OA. Sodium hypochlorite versus formocresol in primary molars pulpotomies: a randomized clinical trial. Eur J Paediatr Dent. 2013;14(1):33-6.

- Shabzendedar M, Mazhari F, Alami M, Talebi M. Sodium hypochlorite vs formocresol as pulpotomy medicaments in primary molars: 1-year follow-up. Pediatr Dent. 2013;35(4):329-32.

- EK Hui Derksen, Chiung-Fen Chen, Majewski R, Ruwaida GH, Boyton J. Retrospective record review: reinforced zinc oxide-eugenol pulpotomy: a retrospective study. Pediatr Dent. 2013;35(1):43-6.

- Jayam C, Mitra M, Mishra J, Bhattacharya B, Jana B. Evaluation and comparison of white mineral trioxide aggregate and formocresol medicaments in primary tooth pulpotomy: clinical and radiographic study. J Indian Soc Pedod Prev Dent. 2014;32(1):13-8.

- Mohammad SG, Raheel SA, Baroudi K. Clinical and radiographic evaluation of Allium sativum Oil as a new medicament for vital pulp treatment of primary teeth. J Int Oral Health. 2014;6(6):32-6.

- Marghalani AA, Omar S, Chen JW. Clinical and radiographic success of mineral trioxide aggregate compared with formocresol as a pulpotomy treatment in primary molars: a systematic review and meta-analysis. J Am Dent Assoc. 2014;145(7):714-21.

- Yadav P, Indushekar K, Saraf B, Sheoran N, Sardana D. Comparative evaluation of ferric sulfate, electrosurgical and diode laser on human primary molars pulpotomy: an "in-vivo" study. Laser Ther. 2014;23(1):41-7.

- Akcay M, Sari S. The effect of sodium hypochlorite application on the success of calcium hydroxide and mineral trioxide aggregate pulpotomies in primary teeth. Pediatr Dent. 2014;36(4):316-21.

- American Academy of Pediatric Dentistry. Guideline on pulp therapy for primary and immature permanent teeth. Reference manual.2014;38(6):280-8.

- De Rossi A, Silva LA, Gatón-Hernández P, Sousa-Neto MD, Nelson-Filho P, Silva RA, et al. Comparison of pulpal responses to pulpotomy and pulp capping with biodentine and mineral trioxide aggregate in dogs. J Endod. 2014;40(9):1362-9.

- Yildiz E, Tosun G. Evaluation of formocresol, calcium hydroxide, ferric sulfate, and MTA primary molar pulpotomies. Eur J Dent. 2014;8(2):234-40.

- Asgary S, Shirvani A, Fazlyab M. MTA and ferric sulfate in pulpotomy outcomes of primary molars: a systematic review and meta-analysis. J of Clin Ped Dent. 2014; 39(1):1-8.

- Durmus B, Tanboga I. In vivo evaluation of the treatment outcome of pulpotomy in primary molars using diode laser, formocresol, and ferric sulphate. Photomed Laser Surg. 2014;32(5):289-95.

- Shirvani A, Hassanizadeh R, Asgary S. Mineral trioxide aggregate vs. calcium hydroxide in primary molar pulpotomy: A systematic review. Iran Endod J. 2014;9(2):83-8.

- Lin P-Y, Chen HS, Wang YH, Tu YK. Primary molar pulpotomy: A systematic review and network meta-analysis. J Dent. 2014;42(9):1060-77. 
- Khorakian F, Mazhari F, Asgary S, Sahebnasagh M, Alizadeh Kaseb A, Movahhed T, et al. Two-year outcomes of electrosurgery and calcium-enriched mixture pulpotomy in primary teeth: a randomised clinical trial. Eur Arch Paediatr Dent. 2014;15(4):223-8.

- $\quad$ Kang CM, Kim SH, Shin Y, Lee HS, Lee JH, Kim GT, et al. A randomized controlled trial of ProRoot MTA, OrthoMTA and RetroMTA for pulpotomy in primary molars. Oral Dis. 2015;21(6):785-91.

- $\quad$ Parisay I, Ghoddusi J, Forghani M. A review on vital pulp therapy in primary teeth. Iran Endod J. 2015;10(4):6-15.

- Pimenta HC, Borges ÁH, Bandeca MC, Neves AT, Fontes RG, da Silva PV, et al. Antimicrobial activity of filling materials used in primary teeth pulpotomy. J Int Oral Health. 2015;7(4):54-7.

- Omar S. MTA, formocresol, and ferric sulfate have significantly better clinical and radiographic outcomes than calcium hydroxide and laser therapies in primary molar pulpotomies after 18-24 months. J Evid Based Dent Pract. 2015;15(2):58-60.

- Mohammad SG, Baroudi K. Bacteriological evaluation of Allium sativum oil as a new medicament for pulpotomy of primary teeth. J Int Soc Prev Community Dent. 2015;5(2):125-30.

- Kusum B, Rakesh K, Richa K. Clinical and radiographical evaluation of mineral trioxide aggregate, biodentine and propolis as pulpotomy medicaments in primary teeth. Rest Dent Endod. 2015;40(4):276-85.

- Fernandes AP, Lorenço N, Marques N, Moretti S, Sakai VT, Silva T et al. Clinical and radiographic outcomes of the use of Low-Level Laser Therapy in vital pulp of primary teeth. Int J Paediatr Dent. 2015;25(2):144-50.

- Lourenço N, Marques NC, Fernandes AP, Hungaro Duarte MA, Abdo RC, Machado MA, et al. Clinical and radiographic evaluation of Portland cement added to radiopacifying agents in primary molar pulpotomies. Eur Arch Paediatr Dent. 2015;16(5):377-82

- $\quad$ Niranjani K, Prasad M, Vasa A, Divya G, Thakur M, Saujanya K. Clinical evaluation of success of primary teeth pulpotomy using mineral trioxide aggregate, laser and biodentine-an in vivo study. J Clin Diagn Res. 2015;9(4):35-7.

- $\quad$ Lee H, Shin Y, Kim SO, Lee HS, Choi HJ, Song JS. Comparative study of pulpal responses to pulpotomy with ProRoot MTA, RetroMTA, and TheraCal in Dogs' Teeth. J Endod. 2015;41(8):1317-24.

- Kenchappa M, Gupta S, Gupta P, Sharma P. Dentine in a capsule: clinical case reports. J Indian Soc Ped and Prev Dent. 2015;33(3):250-4.

- $\quad$ Olatosi OO, Sote EO, Orenuga OO. Effect of mineral trioxide aggregate and formocresol pulpotomy on vital primary teeth: a clinical and radiographic study. Nigerian J Clin Pract. 2015;18(2):292-6.

- Stringhini Junior E, Vitcel ME, Oliveira LB. Evidence of pulpotomy in primary teeth comparing MTA, calcium hydroxide, ferric sulphate, and electrosurgery with formocresol. Eur Arch Paediatr Dent. 2015;16(4):303-12.

- Gupta G, Rana V, Srivastava N, Chandna P. Laser pulpotomy-an effective alternative to conventional techniques: A 12 Months clinicoradiographic study. Int J Clin Pediatr Dent. 2015;8(1):18-21.

- Marques NC, Neto NL, Rodini O, Fernandes AP, Sakai VT, Machado MA et al. Low-level laser therapy as an alternative for pulpotomy in human primary teeth. Lasers Med Sci. 2015;30(7):1815-22.

- Marques N. Pulp tissue response to Portland cement associated with different radio pacifying agents on pulpotomy of human primary molars. J Microsc. 2015;260(3):281-6.

- Martens L, Rajasekharan S, Cauwels R. Pulp management after traumatic injuries with a tricalcium silicate-based cement (Biodentine ${ }^{\mathrm{TM}}$ ): a report of two cases, up to 48 months follow-up. Eur Arch Paediatr Dent. 2015;16(6):491-6.

- Al-Dlaigan YH. Pulpotomy medicaments used in deciduous dentition: An update. J Contemp Dent Pract. 2015;16(6):486-503.

- $\quad$ Farsi D, El-Khodary H, Farsi N, El Ashiry E, Yahmoor M, Alzain S. Sodium hypochlorite versus formocresol and ferric sulfate pulpotomies in primary molars: 18 month follow up. Pediatr Dent. 2015;37(7):535-40.

- Camilleri J. Staining potential of Neo MTA Plus, MTA Plus, and Biodentine used for pulpotomy procedures. J Endod. 2015;41(7):1139-45.

- $\quad$ Bhagat D, Sunder RK, Devendrappa SN, Vanka A, Choudaha N. A comparative evaluation of ProRoot mineral trioxide aggregate and Portland cement as a pulpotomy medicament. J Indian Soc Pedod Prev Dent. 2016;34(2):172-6.

- Togaru H, Muppa R, Srinivas N, Naveen K, Reddy VK, Rebecca VC. Clinical and radiographic evaluation of success of two commercially available pulpotomy agents in primary teeth: An in vivo study. J Contemp Dent Pract. 2016;17(7):55763.

- Goyal P, Pandit IK, Gugnani N, Gupta M, Gambhir R. Clinical and radiographic comparison of various medicaments used for pulpotomy in primary molars: a randomized clinical trial. Eur J Dent. 2016;10(3):315-20.

- Yildirim C, Basak F, Akgun OM, Polat GG, Altun C. Clinical and radiographic evaluation of the effectiveness of formocresol, mineral trioxide aggregate, portland cement, and enamel matrix derivative in primary teeth pulpotomies: a two year follow-up. J Clin Pediatr Dent. 2016;40(1):14-20.

- Uloopi KS, Vinay C, Ratnaditya A, Gopal AS, Mrudula KJ, Rao RC. Clinical evaluation of Low-Level Diode Laser application for primary teeth pulpotomy. J Clin Diagn Res. 2016;10(1):67-70.

- Musale P, Soni A. Clinical pulpotomy trial of Capaifera Langsdorffii Oil Resin versus formocresol and White Mineral Trioxide Aggregate in primary teeth. Pediatr Dent. 2016;38(2):5-12.

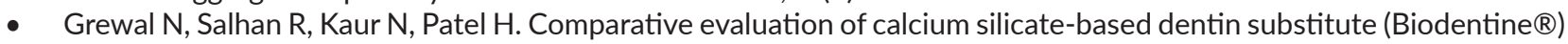
and calcium hydroxide (pulpdent) in the formation of reactive dentin bridge in regenerative pulpotomy of vital primary teeth: triple blind, randomized clinical trial. Contemp Clin Dent. 2016; 7(4):457-63. 
- $\quad$ El Meligy O, Allazzam S, Alamoudi N. Comparison between biodentine and formocresol for pulpotomy of primary teeth: a randomized clinical trial. Quintessence Int Pediatr Dent. 2016;47(7):571-80.

- Daltoé MO, Paula-Silva FW, Faccioli LH, Gatón-Hernández PM, De Rossi A, Bezerra-Silva LA. Expression of mineralization markers during pulp response to Biodentine and mineral trioxide aggregate. J Endod. 2016;42(4):596-603.

- Al-Haj Ali SN. In vitro toxicity of propolis in comparison with other primary teeth pulpotomy agents on human fibroblasts. J Investig Clin Dent. 2016;7(3):308-13.

- Wunsch PB, Kuhnen MM, Best AM, Brickhouse TH. Retrospective study of the survival rates of indirect pulp therapy versus different pulpotomy medicaments. Pediatr Dent. 2016;15(5):406-11.

- Cuadros-Fernández C, Lorente-Rodríguez Al, Sáez-Martínez S, García-Binimelis J, About I, Mercadé M. Short-term treatment outcome of pulpotomies in primary molars using mineral trioxide aggregate and Biodentine: a randomized clinical trial. Clin Oral Investig. 2016;20(7):1639-45.

- $\quad$ Godhi B, Tyagi R. Success rate of MTA pulpotomy on vital pulp of primary molars: a 3-year observational study. Int J Clin Pediatr Dent. 2016;9(3):222-7.

- Gonzalez-Lara A, Ruiz-Rodriguez MS, Pierdant-Perez M, Garrocho-Rangel JA, Pozos-Guillen AJ. Zinc oxide-eugenol pulpotomy in primary teeth: A 24-month follow-up. J Clin Pediatr Dent. 2016; 40(2):107-12.

- Dhar V, Marghalani AA, Crystal YO, Kumar A, Ritwik P, Tulunoglu O, et al.Use of vital pulp therapies in primary teeth with deep caries lesions. Pediatr Dent. 2017;15:39(5):146-59.

- Ozmen B, Bayrak S. Comparative evaluation of ankafers blood stopper, ferric sulfate, and formocresol as pulpotomy agent in primary teeth: a clinical study. Niger J Clin Pract. 2017;20(7):832-8.

- $\quad$ Kathal S, Gupta S, Bhayya DP, Rao A, Roy AP, Sabhlok A. A comparative evaluation of clinical and radiographic success rate of pulpotomy in primary molars using antioxidant mix and mineral trioxide aggregate: An in vivo 1-year follow-up study. J Indian Soc Pedod Prev Dent. 2017;35(4):327-31.

- $\quad$ Beretta M, Federici Canova F. A new method for deep caries treatment in primary teeth using ozone: a retrospective study. Eur J Paediatr Dent. 2017;18(2):111-5.

- Sunitha B, Puppala R, Kethineni B, K Mallela M, Peddi R, Tarasingh P. Clinical and radiographic evaluation of four different pulpotomy agents in primary molars: a longitudinal study. Int J Clin Pediatr Dent. 2017;10(3):240-4.

- $\quad$ Purohit RN, Bhatt M, Purohit K, Acharya J, Kumar R, Garg R. Clinical and radiological evaluation of turmeric powder as a pulpotomy medicament in primary teeth: an in vivo study. Int J Clin Pediatr Dent. 2017;10(1):37-40.

- Juneja P, Kulkarni S. Clinical and radiographic comparison of biodentine, mineral trioxide aggregate and formocresol as pulpotomy agents in primary molars. Eur Arch Paediatr Dent. 2017;18(4):271-8.

- $\quad$ Patidar S, Kalra N, Khatri A, Tyagi R. Clinical and radiographic comparison of platelet-rich fibrin and mineral trioxide aggregate as pulpotomy agents in primary molars. J Indian Soc Pedod Prev Dent. 2017;35(4):367-73.

- Collado-González M, García-Bernal D, Oñate-Sánchez RE, Ortolani-Seltenerich PS, Álvarez-Muro T, Lozano A, et al. Cytotoxicity and bioactivity of various pulpotomy materials on stem cell from human exfoliated primary teeth. Int Endod J. 2017;50(2):19-30.

- Hugar SM, Kukreja P, Hugar SS, Gokhale N, Assudani H. Comparative evaluation of clinical and radiographic success of formocresol, propolis, turmeric gel, and calcium hydroxide on pulpotomized primary molars: A preliminary study. Int J Clin Pediatr Dent. 2017;10(1):18-23.

- $\quad$ Kalra M, Garg N, Rallan M, Pathivada L, Yeluri R. Comparative evaluation of fresh aloe barbadensis plant extract and mineral trioxide aggregate as pulpotomy agents in primary molars: A 12-month follow-up study. Contemp Clin Dent. 2017;8(1):106-11.

- Sirohi K, Marwaha M, Gupta A, Bansal K, Srivastava A. Comparison of clinical and radiographic success rates of pulpotomy in primary molars using ferric sulfate and bioactive tricalcium silicate cement: an in vivo study. Int J Clin Pediatr Dent. 2017;10(2):147-51.

- Chauhan SP, Gupta M, Ahmed H, Tongya R, Sharma D, Chugh B. Evaluation and comparison between formocresol and sodium hypochlorite as pulpotomy medicament: A randomized study. J Contemp Dent Pract. 2017;18(11):1029-33.

- $\quad$ Bakhtiar H, Nekoofar MH, Aminishakib P, Abedi F, Naghi Moosavi F, Esnaashari E, et al. Human pulp responses to partial pulpotomy treatment with TheraCal as compared with Biodentine and ProRoot MTA: a clinical trial. J Endod. 2017;43(11):1786-91.

- $\quad$ Keles S, Kocaturk O. Immediate postoperative pain and recovery time after pulpotomy performed under general anaesthesia in young children. Pain Res Manag. 2017;8(1):1-6.

- Hugar SM, Reddy R, Deshpande SD, Shigli A, Gokhale NS, Hugar SS. In vivo comparative evaluation of mineral trioxide aggregate and formocresol pulpotomy in primary molars: A 60-month follow-up study. Contemp Clin Dent. 2017;8(1):122-7.

- $\quad$ Shafie L, Barghi H, Parirokh M, Ebrahimnejad H, Nakhae N, Esmaili S. Postoperative pain following pulpotomy of primary molars with two biomaterials: A randomized split mouth clinical trial. Iran Endod J. 2017;12(1):10-4.

- Coll J, Seale N, Vargas K, Marghalani A, Shamali S, Graham L. Primary tooth vital pulp therapy: A systematic review and meta-analysis. Pediatr Dent. 2017; 39(1):16-27.

- $\quad$ Sivadas S, Rao A, Natarajan S, Shenoy R, Srikrishna SB. Pulpal response to ferric sulfate and diode laser when used as pulpotomy agent: An in vivo study. J Clin Diagn Res. 2017;11(6):87-91. 
- Rajasekharan S, Martens LC, Vandenbulcke J, Jacquet W, Bottenberg P, Cauwels RG. Efficacy of three different pulpotomy agents in primary molars: a randomized control trial. Int Endod J. 2017;50(3):215-28.

- Monteiro J, Ní Chaollaí A, Duggal M. The teaching of management of the pulp in primary molars across Europe. Eur Arch Paediatr Dent. 2017;18(3):203-8.

- $\quad$ Bani M, Aktas N, Çinarç C, Odabas ME. The clinical and radiographic success of primary molar pulpotomy using BiodentineTM and mineral trioxide aggregate: a 24-month randomized clinical trial. Pediatr Dent. 2017;39(4):284-8. 
Anexo 2. Afiliación de los primeros autores firmantes de los artículos seleccionados y su porcentaje de producción global por década entre 1960 y 2017.

\begin{tabular}{|c|c|c|c|c|c|c|c|}
\hline \multirow{2}{*}{ Institución } & \multicolumn{7}{|c|}{ Décadas } \\
\hline & $1960-1969$ & 1970-1979 & 1980-1989 & 1990-1999 & 2000-2009 & 2010-2017 & $1960-2017$ \\
\hline $\begin{array}{l}\text { A.B. Shetty Memorial Institute } \\
\text { of Dental Sciences (India) }\end{array}$ & $0,00 \%$ & $0,00 \%$ & $0,00 \%$ & $0,35 \%$ & $0,00 \%$ & $0,00 \%$ & $0,35 \%$ \\
\hline $\begin{array}{l}\text { Aashirwad Nursing Home } \\
\text { (India) }\end{array}$ & $0,00 \%$ & $0,00 \%$ & $0,00 \%$ & $0,00 \%$ & $0,00 \%$ & $0,35 \%$ & $0,35 \%$ \\
\hline $\begin{array}{l}\text { Adnan Menderes University } \\
\text { (Turquía) }\end{array}$ & $0,00 \%$ & $0,00 \%$ & $0,00 \%$ & $0,00 \%$ & $0,00 \%$ & $0,35 \%$ & $0,35 \%$ \\
\hline $\begin{array}{l}\text { Aix Marseille Université } \\
\text { (Francia) }\end{array}$ & $0,00 \%$ & $0,00 \%$ & $0,00 \%$ & $0,00 \%$ & $0,00 \%$ & $0,35 \%$ & $0,35 \%$ \\
\hline $\begin{array}{l}\text { Al-Amiri Dental Center } \\
\text { (Kuwait) }\end{array}$ & $0,00 \%$ & $0,00 \%$ & $0,00 \%$ & $0,00 \%$ & $0,70 \%$ & $0,00 \%$ & $0,70 \%$ \\
\hline Al-Azhar University (Egipto) & $0,00 \%$ & $0,00 \%$ & $0,00 \%$ & $0,00 \%$ & $0,00 \%$ & $0,70 \%$ & $0,70 \%$ \\
\hline $\begin{array}{l}\text { Al-Farabi College of Dentistry } \\
\& \text { Nursing (Arabia Saudita) }\end{array}$ & $0,00 \%$ & $0,00 \%$ & $0,00 \%$ & $0,00 \%$ & $0,00 \%$ & $0,35 \%$ & $0,35 \%$ \\
\hline Alexandria University (Egipto) & $0,00 \%$ & $0,00 \%$ & $0,00 \%$ & $0,00 \%$ & $0,70 \%$ & $0,00 \%$ & $0,70 \%$ \\
\hline $\begin{array}{l}\text { American Academy of } \\
\text { Pediatric Dentistry (EE.UU.) }\end{array}$ & $0,00 \%$ & $0,00 \%$ & $0,00 \%$ & $0,00 \%$ & $0,00 \%$ & $0,35 \%$ & $0,35 \%$ \\
\hline Ankara University (Turquía) & $0,00 \%$ & $0,00 \%$ & $0,00 \%$ & $0,00 \%$ & $0,35 \%$ & $0,35 \%$ & $0,70 \%$ \\
\hline $\begin{array}{l}\text { Anoor Dental College } \\
\text { Moovattupuzha (India) }\end{array}$ & $0,00 \%$ & $0,00 \%$ & $0,00 \%$ & $0,00 \%$ & $0,00 \%$ & $0,35 \%$ & $0,35 \%$ \\
\hline Athens University (Grecia) & $0,00 \%$ & $0,00 \%$ & $0,00 \%$ & $0,00 \%$ & $0,70 \%$ & $0,00 \%$ & $0,70 \%$ \\
\hline $\begin{array}{l}\text { Azad University of Medical } \\
\text { Sciences (Irán) }\end{array}$ & $0,00 \%$ & $0,00 \%$ & $0,00 \%$ & $0,00 \%$ & $0,33 \%$ & $0,00 \%$ & $0,33 \%$ \\
\hline $\begin{array}{l}\text { Bauru School of Dentistry } \\
\text { (Brasil) }\end{array}$ & $0,00 \%$ & $0,00 \%$ & $0,00 \%$ & $0,00 \%$ & $0,00 \%$ & $1,05 \%$ & $1,05 \%$ \\
\hline $\begin{array}{l}\text { Bharti Vidyapeeths Institute of } \\
\text { Dental Sciences (India) }\end{array}$ & $0,00 \%$ & $0,00 \%$ & $0,00 \%$ & $0,00 \%$ & $0,00 \%$ & $0,70 \%$ & $0,70 \%$ \\
\hline Cairo University (Egipto) & $0,00 \%$ & $0,00 \%$ & $0,00 \%$ & $0,00 \%$ & $0,00 \%$ & $0,35 \%$ & $0,35 \%$ \\
\hline $\begin{array}{l}\text { Centre for Dental Education } \\
\text { and Research, AllMS (India) }\end{array}$ & $0,00 \%$ & $0,00 \%$ & $0,00 \%$ & $0,00 \%$ & $0,00 \%$ & $0,35 \%$ & $0,35 \%$ \\
\hline $\begin{array}{l}\text { Chiang Mai University } \\
\text { (Tailandia) }\end{array}$ & $0,00 \%$ & $0,00 \%$ & $0,00 \%$ & $0,00 \%$ & $0,00 \%$ & $0,35 \%$ & $0,35 \%$ \\
\hline $\begin{array}{l}\text { Christian Dental College, } \\
\text { Ludhiana (India) }\end{array}$ & $0,00 \%$ & $0,00 \%$ & $0,00 \%$ & $0,00 \%$ & $0,35 \%$ & $0,00 \%$ & $0,35 \%$ \\
\hline $\begin{array}{l}\text { Chulalongkorn University } \\
\text { (Tailandia) }\end{array}$ & $0,00 \%$ & $0,00 \%$ & $0,00 \%$ & $0,00 \%$ & $0,00 \%$ & $1,05 \%$ & $1,05 \%$ \\
\hline $\begin{array}{l}\text { CKS Theja Institute of Dental } \\
\text { Sciences and Research (India) }\end{array}$ & $0,00 \%$ & $0,00 \%$ & $0,00 \%$ & $0,00 \%$ & $0,00 \%$ & $0,70 \%$ & $0,70 \%$ \\
\hline $\begin{array}{l}\text { College of Dental Sciences } \\
\text { and Research Centre Sanand } \\
\text { (India) }\end{array}$ & $0,00 \%$ & $0,00 \%$ & $0,00 \%$ & $0,00 \%$ & $0,00 \%$ & $0,35 \%$ & $0,35 \%$ \\
\hline Dalhousie University (Canadá) & $0,00 \%$ & $0,00 \%$ & $0,00 \%$ & $0,00 \%$ & $0,00 \%$ & $0,35 \%$ & $0,35 \%$ \\
\hline Dental Clinic Esdens (España) & $0,00 \%$ & $0,00 \%$ & $0,00 \%$ & $0,00 \%$ & $0,00 \%$ & $0,35 \%$ & $0,35 \%$ \\
\hline
\end{tabular}




\section{Anexo 2. Afiliación de los primeros autores firmantes de los artículos seleccionados y su porcentaje de producción global por década entre 1960 y 2017.}

\begin{tabular}{|c|c|c|c|c|c|c|c|}
\hline \multirow{2}{*}{ Institución } & \multicolumn{7}{|c|}{ Décadas } \\
\hline & $1960-1969$ & $1970-1979$ & 1980-1989 & 1990-1999 & 2000-2009 & 2010-2017 & $1960-2017$ \\
\hline $\begin{array}{l}\text { Eastman Dental Center, } \\
\text { Rochester, NY (EE.UU.) }\end{array}$ & $0,35 \%$ & $0,00 \%$ & $0,00 \%$ & $0,00 \%$ & $0,00 \%$ & $0,00 \%$ & $0,35 \%$ \\
\hline $\begin{array}{l}\text { Faculty of Dental Sciences, } \\
K, G^{\prime} \text { ' Medical College (India) }\end{array}$ & $0,00 \%$ & $0,00 \%$ & $0,35 \%$ & $0,00 \%$ & $0,00 \%$ & $0,00 \%$ & $0,35 \%$ \\
\hline $\begin{array}{l}\text { Faculty of Dentistry Gazi } \\
\text { Univeristy (Turquía) }\end{array}$ & $0,00 \%$ & $0,00 \%$ & $0,35 \%$ & $0,00 \%$ & $0,00 \%$ & $0,00 \%$ & $0,35 \%$ \\
\hline $\begin{array}{l}\text { Faculty of Dentistry Kind } \\
\text { Abdulaziz University (Arabia } \\
\text { Saudita) }\end{array}$ & $0,00 \%$ & $0,00 \%$ & $0,00 \%$ & $0,00 \%$ & $0,35 \%$ & $0,00 \%$ & $0,35 \%$ \\
\hline $\begin{array}{l}\text { Federal University of Alfenas } \\
\text { (Brasil) }\end{array}$ & $0,00 \%$ & $0,00 \%$ & $0,00 \%$ & $0,00 \%$ & $0,00 \%$ & $0,70 \%$ & $0,70 \%$ \\
\hline $\begin{array}{l}\text { Free University of Brussels } \\
\text { (Bélgica) }\end{array}$ & $0,00 \%$ & $0,00 \%$ & $0,00 \%$ & $0,00 \%$ & $0,00 \%$ & $0,35 \%$ & $0,35 \%$ \\
\hline $\begin{array}{l}\text { Gaziantep University } \\
\text { (Turquía) }\end{array}$ & $0,00 \%$ & $0,00 \%$ & $0,00 \%$ & $0,00 \%$ & $0,00 \%$ & $0,35 \%$ & $0,35 \%$ \\
\hline Ghent University (Bélgica) & $0,00 \%$ & $0,00 \%$ & $0,00 \%$ & $0,00 \%$ & $0,00 \%$ & $1,39 \%$ & $1,39 \%$ \\
\hline $\begin{array}{l}\text { Government Dental College } \\
\text { Kottayam (India) }\end{array}$ & $0,00 \%$ & $0,00 \%$ & $0,00 \%$ & $0,00 \%$ & $0,00 \%$ & $0,35 \%$ & $0,35 \%$ \\
\hline $\begin{array}{l}\text { Gulhane Medical Academy } \\
\text { (Turquía) }\end{array}$ & $0,00 \%$ & $0,00 \%$ & $0,00 \%$ & $0,35 \%$ & $0,35 \%$ & $0,35 \%$ & $1,05 \%$ \\
\hline $\begin{array}{l}\text { Hacettepe University } \\
\text { (Turquía) }\end{array}$ & $0,00 \%$ & $0,00 \%$ & $0,00 \%$ & $0,00 \%$ & $0,00 \%$ & $0,35 \%$ & $0,35 \%$ \\
\hline $\begin{array}{l}\text { Hadassah Faculty of Dental } \\
\text { Medicine (Israel) }\end{array}$ & $0,00 \%$ & $0,00 \%$ & $0,70 \%$ & $1,39 \%$ & $1,39 \%$ & $0,35 \%$ & $3,83 \%$ \\
\hline $\begin{array}{l}\text { Hitkarini Dental College and } \\
\text { Hospital (India) }\end{array}$ & $0,00 \%$ & $0,00 \%$ & $0,00 \%$ & $0,00 \%$ & $0,00 \%$ & $0,70 \%$ & $0,70 \%$ \\
\hline $\begin{array}{l}\text { HKEDT Dental College (EE. } \\
\text { UU.) }\end{array}$ & $0,00 \%$ & $0,00 \%$ & $0,00 \%$ & $0,00 \%$ & $0,00 \%$ & $0,35 \%$ & $0,35 \%$ \\
\hline Ibirapuera University (Brasil) & $0,00 \%$ & $0,00 \%$ & $0,00 \%$ & $0,00 \%$ & $0,35 \%$ & $0,00 \%$ & $0,35 \%$ \\
\hline $\begin{array}{l}\text { Index Institute of Dental } \\
\text { Sciences, Indore (India) }\end{array}$ & $0,00 \%$ & $0,00 \%$ & $0,00 \%$ & $0,00 \%$ & $0,00 \%$ & $0,35 \%$ & $0,35 \%$ \\
\hline Indiana University (EE.UU.) & $0,00 \%$ & $0,00 \%$ & $0,00 \%$ & $0,00 \%$ & $0,35 \%$ & $0,00 \%$ & $0,35 \%$ \\
\hline $\begin{array}{l}\text { Indiana University School of } \\
\text { Dentistry (EE.UU.) }\end{array}$ & $0,35 \%$ & $0,00 \%$ & $0,00 \%$ & $0,00 \%$ & $0,70 \%$ & $0,00 \%$ & $1,05 \%$ \\
\hline $\begin{array}{l}\text { Iranian Center of Endodontic } \\
\text { Research (Irán) }\end{array}$ & $0,00 \%$ & $0,00 \%$ & $0,00 \%$ & $0,00 \%$ & $0,00 \%$ & $1,05 \%$ & $1,05 \%$ \\
\hline Istanbul University (Turquía) & $0,00 \%$ & $0,00 \%$ & $0,00 \%$ & $0,00 \%$ & $0,00 \%$ & $1,05 \%$ & $1,05 \%$ \\
\hline $\begin{array}{l}\text { Izmir Katip Celebi University } \\
\text { (Turquía) }\end{array}$ & $0,00 \%$ & $0,00 \%$ & $0,00 \%$ & $0,00 \%$ & $0,00 \%$ & $0,35 \%$ & $0,35 \%$ \\
\hline Jaipur Dental College (India) & $0,00 \%$ & $0,00 \%$ & $0,00 \%$ & $0,00 \%$ & $0,00 \%$ & $0,70 \%$ & $0,70 \%$ \\
\hline $\begin{array}{l}\text { Kerman Neuroscience } \\
\text { Research Center (Irán) }\end{array}$ & $0,00 \%$ & $0,00 \%$ & $0,00 \%$ & $0,00 \%$ & $0,00 \%$ & $0,35 \%$ & $0,35 \%$ \\
\hline $\begin{array}{l}\text { Kerman University of } \\
\text { Medical Sciences (Irán) }\end{array}$ & $0,00 \%$ & $0,00 \%$ & $0,00 \%$ & $0,00 \%$ & $0,00 \%$ & $0,35 \%$ & $0,35 \%$ \\
\hline
\end{tabular}


Anexo 2. Afiliación de los primeros autores firmantes de los artículos seleccionados y su porcentaje de producción global por década entre 1960 y 2017.

\begin{tabular}{|c|c|c|c|c|c|c|c|}
\hline \multirow{2}{*}{ Institución } & \multicolumn{7}{|c|}{ Décadas } \\
\hline & $1960-1969$ & $1970-1979$ & 1980-1989 & $1990-1999$ & 2000-2009 & 2010-2017 & $1960-2017$ \\
\hline $\begin{array}{l}\text { King Abdulaziz University } \\
\text { (Arabia Saudita) }\end{array}$ & $0,00 \%$ & $0,00 \%$ & $0,00 \%$ & $0,00 \%$ & $0,00 \%$ & $0,70 \%$ & $0,70 \%$ \\
\hline $\begin{array}{l}\text { King George's Medical } \\
\text { University (Reino Unido) }\end{array}$ & $0,00 \%$ & $0,00 \%$ & $0,00 \%$ & $0,00 \%$ & $0,00 \%$ & $0,70 \%$ & $0,70 \%$ \\
\hline $\begin{array}{l}\text { King Khalid Univeristy (Arabia } \\
\text { Saudita) }\end{array}$ & $0,00 \%$ & $0,00 \%$ & $0,00 \%$ & $0,00 \%$ & $0,00 \%$ & $0,35 \%$ & $0,35 \%$ \\
\hline $\begin{array}{l}\text { King Saud University (Arabia } \\
\text { Saudita) }\end{array}$ & $0,00 \%$ & $0,00 \%$ & $0,00 \%$ & $0,00 \%$ & $0,00 \%$ & $0,70 \%$ & $0,70 \%$ \\
\hline $\begin{array}{l}\text { KLE VK Institute of Dental } \\
\text { Sciences (India) }\end{array}$ & $0,00 \%$ & $0,00 \%$ & $0,00 \%$ & $0,00 \%$ & $0,00 \%$ & $1,05 \%$ & $1,05 \%$ \\
\hline $\begin{array}{l}\text { Kyung Hee University (Corea } \\
\text { del Sur) }\end{array}$ & $0,00 \%$ & $0,00 \%$ & $0,00 \%$ & $0,00 \%$ & $0,00 \%$ & $0,35 \%$ & $0,35 \%$ \\
\hline $\begin{array}{l}\text { Leeds Dental Institute UK } \\
\text { (Reino Unido) }\end{array}$ & $0,00 \%$ & $0,00 \%$ & $0,00 \%$ & $0,00 \%$ & $0,35 \%$ & $0,00 \%$ & $0,35 \%$ \\
\hline $\begin{array}{l}\text { Leeds School of Dentistry } \\
\text { (Reino Unido) }\end{array}$ & $0,00 \%$ & $0,00 \%$ & $0,00 \%$ & $0,00 \%$ & $0,00 \%$ & $0,35 \%$ & $0,35 \%$ \\
\hline $\begin{array}{l}\text { Loma Linda University (EE. } \\
\text { UU.) }\end{array}$ & $0,00 \%$ & $0,00 \%$ & $0,00 \%$ & $0,00 \%$ & $0,00 \%$ & $0,70 \%$ & $0,70 \%$ \\
\hline Mamata Dental College (India) & $0,00 \%$ & $0,00 \%$ & $0,00 \%$ & $0,00 \%$ & $0,00 \%$ & $0,35 \%$ & $0,35 \%$ \\
\hline $\begin{array}{l}\text { Manipal University Mangalore } \\
\text { (India) }\end{array}$ & $0,00 \%$ & $0,00 \%$ & $0,00 \%$ & $0,00 \%$ & $0,00 \%$ & $0,35 \%$ & $0,35 \%$ \\
\hline $\begin{array}{l}\text { Mashhad University of Medical } \\
\text { Sciences (Irán) }\end{array}$ & $0,00 \%$ & $0,00 \%$ & $0,00 \%$ & $0,35 \%$ & $0,35 \%$ & $1,74 \%$ & $2,44 \%$ \\
\hline $\begin{array}{l}\text { Maulana Azad Institute of } \\
\text { Dental Sciences (India) }\end{array}$ & $0,00 \%$ & $0,00 \%$ & $0,00 \%$ & $0,00 \%$ & $0,00 \%$ & $0,35 \%$ & $0,35 \%$ \\
\hline Minia University (Egipto) & $0,00 \%$ & $0,00 \%$ & $0,00 \%$ & $0,00 \%$ & $0,00 \%$ & $0,35 \%$ & $0,35 \%$ \\
\hline $\begin{array}{l}\text { MM College of Dental Sciences } \\
\text { and Research (India) }\end{array}$ & $0,00 \%$ & $0,00 \%$ & $0,00 \%$ & $0,00 \%$ & $0,00 \%$ & $0,35 \%$ & $0,35 \%$ \\
\hline $\begin{array}{l}\text { Modem Dental College and } \\
\text { Research Centre, Indore (India) }\end{array}$ & $0,00 \%$ & $0,00 \%$ & $0,00 \%$ & $0,00 \%$ & $0,00 \%$ & $0,35 \%$ & $0,35 \%$ \\
\hline $\begin{array}{l}\text { Mott Foundation Children's } \\
\text { Health Center Manipal } \\
\text { University Mangalore (India) }\end{array}$ & $0,35 \%$ & $0,00 \%$ & $0,00 \%$ & $0,00 \%$ & $0,00 \%$ & $0,00 \%$ & $0,35 \%$ \\
\hline $\begin{array}{l}\text { Nair Hospital Dental College } \\
\text { (India) }\end{array}$ & $0,00 \%$ & $0,00 \%$ & $0,00 \%$ & $0,00 \%$ & $0,35 \%$ & $0,00 \%$ & $0,35 \%$ \\
\hline $\begin{array}{l}\text { National Taiwan University } \\
\text { (Taiwan) }\end{array}$ & $0,00 \%$ & $0,00 \%$ & $0,00 \%$ & $0,00 \%$ & $0,00 \%$ & $0,35 \%$ & $0,35 \%$ \\
\hline $\begin{array}{l}\text { National Yang-Ming University } \\
\text { (Taiwan) }\end{array}$ & $0,00 \%$ & $0,00 \%$ & $0,00 \%$ & $0,00 \%$ & $0,00 \%$ & $0,35 \%$ & $0,35 \%$ \\
\hline $\begin{array}{l}\text { Nort Khorasan University of } \\
\text { Medical Sciences (Irán) }\end{array}$ & $0,00 \%$ & $0,00 \%$ & $0,00 \%$ & $0,00 \%$ & $0,00 \%$ & $0,35 \%$ & $0,35 \%$ \\
\hline $\begin{array}{l}\text { Panineeya Mahavidyalaya } \\
\text { Institute of Dental Sciences } \\
\text { and Research Centre (India) }\end{array}$ & $0,00 \%$ & $0,00 \%$ & $0,00 \%$ & $0,00 \%$ & $0,00 \%$ & $0,70 \%$ & $0,70 \%$ \\
\hline
\end{tabular}




\section{Anexo 2. Afiliación de los primeros autores firmantes de los artículos seleccionados y su porcentaje de producción global por década entre 1960 y 2017.}

\begin{tabular}{|c|c|c|c|c|c|c|c|}
\hline \multirow{2}{*}{ Institución } & \multicolumn{7}{|c|}{ Décadas } \\
\hline & $1960-1969$ & $1970-1979$ & 1980-1989 & 1990-1999 & 2000-2009 & 2010-2017 & $1960-2017$ \\
\hline $\begin{array}{l}\text { Peking University School } \\
\text { and Hospital of Stomatology } \\
\text { (China) }\end{array}$ & $0,00 \%$ & $0,00 \%$ & $0,00 \%$ & $0,00 \%$ & $0,00 \%$ & $0,35 \%$ & $0,35 \%$ \\
\hline Potiguar University (Brasil) & $0,00 \%$ & $0,00 \%$ & $0,00 \%$ & $0,00 \%$ & $0,00 \%$ & $0,35 \%$ & $0,35 \%$ \\
\hline $\begin{array}{l}\text { Monticelli Terme Hospital \& } \\
\text { Clinic (Italia) }\end{array}$ & $0,00 \%$ & $0,00 \%$ & $0,00 \%$ & $0,00 \%$ & $0,00 \%$ & $0,35 \%$ & $0,35 \%$ \\
\hline $\begin{array}{l}\text { Punjab Government Dental } \\
\text { College and Hospital (India) }\end{array}$ & $0,00 \%$ & $0,00 \%$ & $0,00 \%$ & $0,00 \%$ & $0,00 \%$ & $0,35 \%$ & $0,35 \%$ \\
\hline $\begin{array}{l}\text { Qassim University (Arabia } \\
\text { Saudita) }\end{array}$ & $0,00 \%$ & $0,00 \%$ & $0,00 \%$ & $0,00 \%$ & $0,00 \%$ & $0,35 \%$ & $0,35 \%$ \\
\hline $\begin{array}{l}\text { Queen Fabiola Children's } \\
\text { University Hospital (Bélgica) }\end{array}$ & $0,00 \%$ & $0,00 \%$ & $0,00 \%$ & $0,00 \%$ & $0,00 \%$ & $0,35 \%$ & $0,35 \%$ \\
\hline $\begin{array}{l}\text { Rafsanjan University of } \\
\text { Medical Sciences (Irán) }\end{array}$ & $0,00 \%$ & $0,00 \%$ & $0,00 \%$ & $0,00 \%$ & $0,00 \%$ & $0,35 \%$ & $0,35 \%$ \\
\hline $\begin{array}{l}\text { Rangoonwala College of } \\
\text { Dental Sciences and Researach } \\
\text { Centre (India) }\end{array}$ & $0,00 \%$ & $0,00 \%$ & $0,00 \%$ & $0,00 \%$ & $0,00 \%$ & $0,35 \%$ & $0,35 \%$ \\
\hline $\begin{array}{l}\text { Rayat and Bahra Dental } \\
\text { College and Hospital (India) }\end{array}$ & $0,00 \%$ & $0,00 \%$ & $0,00 \%$ & $0,00 \%$ & $0,00 \%$ & $0,35 \%$ & $0,35 \%$ \\
\hline Regas Dental College (India) & $0,00 \%$ & $0,00 \%$ & $0,00 \%$ & $0,00 \%$ & $0,00 \%$ & $0,35 \%$ & $0,35 \%$ \\
\hline $\begin{array}{l}\text { Sadar Patel Medical College } \\
\text { Bikaner (India) }\end{array}$ & $0,00 \%$ & $0,00 \%$ & $0,00 \%$ & $0,00 \%$ & $0,00 \%$ & $0,35 \%$ & $0,35 \%$ \\
\hline $\begin{array}{l}\text { São Leopoldo Mandic School } \\
\text { of Dentistry (Brasil) }\end{array}$ & $0,00 \%$ & $0,00 \%$ & $0,00 \%$ & $0,00 \%$ & $0,00 \%$ & $0,35 \%$ & $0,35 \%$ \\
\hline $\begin{array}{l}\text { School of Clinical Dentistry } \\
\text { Sheffield (Reino Unido) }\end{array}$ & $0,00 \%$ & $0,00 \%$ & $0,00 \%$ & $0,00 \%$ & $0,35 \%$ & $0,00 \%$ & $0,35 \%$ \\
\hline $\begin{array}{l}\text { School of Dentistry UCLA } \\
\text { (EE.UU.) }\end{array}$ & $0,00 \%$ & $0,00 \%$ & $0,35 \%$ & $0,00 \%$ & $0,00 \%$ & $0,00 \%$ & $0,35 \%$ \\
\hline Seluck University (Turquía) & $0,00 \%$ & $0,00 \%$ & $0,00 \%$ & $0,00 \%$ & $0,00 \%$ & $0,35 \%$ & $0,35 \%$ \\
\hline $\begin{array}{l}\text { SGT Dental College, Hospital } \\
\text { and Research Institute (India) }\end{array}$ & $0,00 \%$ & $0,00 \%$ & $0,00 \%$ & $0,00 \%$ & $0,00 \%$ & $0,70 \%$ & $0,70 \%$ \\
\hline $\begin{array}{l}\text { Shahed University od Medical } \\
\text { Sciences (Irán) }\end{array}$ & $0,00 \%$ & $0,00 \%$ & $0,00 \%$ & $0,00 \%$ & $0,00 \%$ & $0,35 \%$ & $0,35 \%$ \\
\hline $\begin{array}{l}\text { Shahid Beheshti University of } \\
\text { Medical Sciences (Irán) }\end{array}$ & $0,00 \%$ & $0,00 \%$ & $0,00 \%$ & $0,00 \%$ & $0,35 \%$ & $2,44 \%$ & $2,79 \%$ \\
\hline $\begin{array}{l}\text { Shetty Memorial Institute Of } \\
\text { Dental Sciences (India) }\end{array}$ & $0,00 \%$ & $0,00 \%$ & $0,00 \%$ & $0,00 \%$ & $0,35 \%$ & $0,00 \%$ & $0,35 \%$ \\
\hline $\begin{array}{l}\text { Shiraz University of Medical } \\
\text { Sciences (Irán) }\end{array}$ & $0,00 \%$ & $0,00 \%$ & $0,00 \%$ & $0,00 \%$ & $0,35 \%$ & $0,70 \%$ & $1,05 \%$ \\
\hline Sichuan University (China) & $0,00 \%$ & $0,00 \%$ & $0,00 \%$ & $0,00 \%$ & $0,35 \%$ & $0,00 \%$ & $0,35 \%$ \\
\hline $\begin{array}{l}\text { Sree Chitra Triunal Institute } \\
\text { for Medical Science and } \\
\text { Technology (India) }\end{array}$ & $0,00 \%$ & $0,00 \%$ & $0,00 \%$ & $0,00 \%$ & $0,00 \%$ & $0,35 \%$ & $0,35 \%$ \\
\hline
\end{tabular}


Anexo 2. Afiliación de los primeros autores firmantes de los artículos seleccionados y su porcentaje de producción global por década entre 1960 y 2017.

\begin{tabular}{|c|c|c|c|c|c|c|c|}
\hline \multirow{2}{*}{ Institución } & \multicolumn{7}{|c|}{ Décadas } \\
\hline & 1960-1969 & 1970-1979 & 1980-1989 & 1990-1999 & $2000-2009$ & 2010-2017 & $1960-2017$ \\
\hline Sree Sai Dental College (India) & $0,00 \%$ & $0,00 \%$ & $0,00 \%$ & $0,00 \%$ & $0,00 \%$ & $0,35 \%$ & $0,35 \%$ \\
\hline $\begin{array}{l}\text { Sri Aurobindo College of } \\
\text { Dentistry (India) }\end{array}$ & $0,00 \%$ & $0,00 \%$ & $0,00 \%$ & $0,00 \%$ & $0,00 \%$ & $0,70 \%$ & $0,70 \%$ \\
\hline $\begin{array}{l}\text { Sri Jagadguru Sri } \\
\text { Shivarathreeshwara University } \\
\text { (India) }\end{array}$ & $0,00 \%$ & $0,00 \%$ & $0,00 \%$ & $0,00 \%$ & $0,00 \%$ & $0,35 \%$ & $0,35 \%$ \\
\hline $\begin{array}{l}\text { Sri Venkata Sai Institute of } \\
\text { Dental Sciences (India) }\end{array}$ & $0,00 \%$ & $0,00 \%$ & $0,00 \%$ & $0,00 \%$ & $0,00 \%$ & $0,35 \%$ & $0,35 \%$ \\
\hline $\begin{array}{l}\text { St, Christopher's Hospital for } \\
\text { Children (EE.UU.) }\end{array}$ & $0,00 \%$ & $0,70 \%$ & $0,00 \%$ & $0,00 \%$ & $0,00 \%$ & $0,00 \%$ & $0,70 \%$ \\
\hline $\begin{array}{l}\text { St, Joseph Dental College } \\
\text { (India) }\end{array}$ & $0,00 \%$ & $0,00 \%$ & $0,00 \%$ & $0,00 \%$ & $0,00 \%$ & $0,35 \%$ & $0,35 \%$ \\
\hline $\begin{array}{l}\text { State University of Gent } \\
\text { (Bélgica) }\end{array}$ & $0,00 \%$ & $0,00 \%$ & $0,35 \%$ & $0,00 \%$ & $0,00 \%$ & $0,00 \%$ & $0,35 \%$ \\
\hline $\begin{array}{l}\text { State University of Paraíba } \\
\text { (Brasil) }\end{array}$ & $0,00 \%$ & $0,00 \%$ & $0,00 \%$ & $0,00 \%$ & $0,00 \%$ & $0,35 \%$ & $0,35 \%$ \\
\hline Subharti Dental College (India) & $0,00 \%$ & $0,00 \%$ & $0,00 \%$ & $0,00 \%$ & $0,35 \%$ & $0,35 \%$ & $0,70 \%$ \\
\hline $\begin{array}{l}\text { Sudha Rustagi College of } \\
\text { Dental Sciences and Research } \\
\text { (India) }\end{array}$ & $0,00 \%$ & $0,00 \%$ & $0,00 \%$ & $0,00 \%$ & $0,00 \%$ & $0,35 \%$ & $0,35 \%$ \\
\hline $\begin{array}{l}\text { Tabriz University of Medical } \\
\text { Sciences (Irán) }\end{array}$ & $0,00 \%$ & $0,00 \%$ & $0,00 \%$ & $0,00 \%$ & $0,35 \%$ & $0,00 \%$ & $0,35 \%$ \\
\hline $\begin{array}{l}\text { Taichung Veterans School } \\
\text { (Taiwan) }\end{array}$ & $0,00 \%$ & $0,00 \%$ & $0,00 \%$ & $0,35 \%$ & $0,35 \%$ & $0,00 \%$ & $0,70 \%$ \\
\hline $\begin{array}{l}\text { Taiwan Adventist Hospital } \\
\text { (Taiwan) }\end{array}$ & $0,00 \%$ & $0,00 \%$ & $0,00 \%$ & $0,00 \%$ & $0,00 \%$ & $0,35 \%$ & $0,35 \%$ \\
\hline $\begin{array}{l}\text { Teerthanker Mahaveer Dental } \\
\text { College and Research Centre } \\
\text { (India) }\end{array}$ & $0,00 \%$ & $0,00 \%$ & $0,00 \%$ & $0,00 \%$ & $0,00 \%$ & $0,35 \%$ & $0,35 \%$ \\
\hline Tehran University (Irán) & $0,00 \%$ & $0,00 \%$ & $0,00 \%$ & $0,00 \%$ & $0,35 \%$ & $0,00 \%$ & $0,35 \%$ \\
\hline $\begin{array}{l}\text { Tehran University of Medical } \\
\text { Sciences (Irán) }\end{array}$ & $0,00 \%$ & $0,00 \%$ & $0,00 \%$ & $0,00 \%$ & $0,70 \%$ & $0,35 \%$ & $1,05 \%$ \\
\hline Tel-Aviv University (Israel) & $0,00 \%$ & $0,00 \%$ & $0,00 \%$ & $0,00 \%$ & $0,00 \%$ & $0,35 \%$ & $0,35 \%$ \\
\hline $\begin{array}{l}\text { Temple University School of } \\
\text { Dentistry (EE.UU.) }\end{array}$ & $0,00 \%$ & $0,35 \%$ & $0,00 \%$ & $0,00 \%$ & $0,00 \%$ & $0,00 \%$ & $0,35 \%$ \\
\hline $\begin{array}{l}\text { Texas A\&M Health Science } \\
\text { Center (EE.UU.) }\end{array}$ & $0,00 \%$ & $0,00 \%$ & $0,00 \%$ & $0,00 \%$ & $0,35 \%$ & $0,70 \%$ & $1,05 \%$ \\
\hline $\begin{array}{l}\text { The Center for Pediatric } \\
\text { Dentisty, Calgary (Canadá) }\end{array}$ & $0,00 \%$ & $0,00 \%$ & $0,00 \%$ & $0,00 \%$ & $0,00 \%$ & $0,35 \%$ & $0,35 \%$ \\
\hline $\begin{array}{l}\text { The Manipal College of Dental } \\
\text { Sciences (India) }\end{array}$ & $0,00 \%$ & $0,00 \%$ & $0,00 \%$ & $0,00 \%$ & $0,35 \%$ & $0,00 \%$ & $0,35 \%$ \\
\hline $\begin{array}{l}\text { The Mott Children's Health } \\
\text { Center (EE.UU.) }\end{array}$ & $0,00 \%$ & $0,00 \%$ & $0,00 \%$ & $0,00 \%$ & $0,00 \%$ & $0,35 \%$ & $0,35 \%$ \\
\hline
\end{tabular}




\section{Anexo 2. Afiliación de los primeros autores firmantes de los artículos seleccionados y su porcentaje de producción global por década entre 1960 y 2017.}

\begin{tabular}{|c|c|c|c|c|c|c|c|}
\hline \multirow{2}{*}{ Institución } & \multicolumn{7}{|c|}{ Décadas } \\
\hline & $1960-1969$ & 1970-1979 & 1980-1989 & 1990-1999 & 2000-2009 & 2010-2017 & $1960-2017$ \\
\hline $\begin{array}{l}\text { The Oxford Dental College, } \\
\text { Hospital and Reasearch Centre } \\
\text { (India) }\end{array}$ & $0,00 \%$ & $0,00 \%$ & $0,00 \%$ & $0,00 \%$ & $0,35 \%$ & $0,00 \%$ & $0,35 \%$ \\
\hline $\begin{array}{l}\text { The University of Adelaide } \\
\text { (Australia) }\end{array}$ & $0,00 \%$ & $0,00 \%$ & $0,35 \%$ & $0,00 \%$ & $0,00 \%$ & $0,00 \%$ & $0,35 \%$ \\
\hline $\begin{array}{l}\text { The University of Alabama at } \\
\text { Birmingham (EE.UU.) }\end{array}$ & $0,00 \%$ & $0,00 \%$ & $0,00 \%$ & $0,00 \%$ & $0,00 \%$ & $0,35 \%$ & $0,35 \%$ \\
\hline $\begin{array}{l}\text { The University of Melbourne } \\
\text { (Australia) }\end{array}$ & $0,00 \%$ & $0,00 \%$ & $0,00 \%$ & $0,00 \%$ & $0,35 \%$ & $0,00 \%$ & $0,35 \%$ \\
\hline $\begin{array}{l}\text { The University of Queensland } \\
\text { (Australia) }\end{array}$ & $0,00 \%$ & $0,00 \%$ & $0,00 \%$ & $0,35 \%$ & $0,00 \%$ & $0,00 \%$ & $0,35 \%$ \\
\hline $\begin{array}{l}\text { The University of Western } \\
\text { Australia (Australia) }\end{array}$ & $0,00 \%$ & $0,00 \%$ & $0,00 \%$ & $0,00 \%$ & $0,00 \%$ & $0,35 \%$ & $0,35 \%$ \\
\hline $\begin{array}{l}\text { Tohoku University School of } \\
\text { Dentistry (Japón) }\end{array}$ & $0,00 \%$ & $0,00 \%$ & $0,35 \%$ & $0,00 \%$ & $0,00 \%$ & $0,00 \%$ & $0,35 \%$ \\
\hline Tsurumi Universiy (Japón) & $0,00 \%$ & $0,00 \%$ & $0,00 \%$ & $0,00 \%$ & $0,00 \%$ & $0,35 \%$ & $0,35 \%$ \\
\hline $\begin{array}{l}\text { UCMS and GTB Hospital } \\
\text { (India) }\end{array}$ & $0,00 \%$ & $0,00 \%$ & $0,00 \%$ & $0,00 \%$ & $0,00 \%$ & $0,35 \%$ & $0,35 \%$ \\
\hline $\begin{array}{l}\text { Univeristy of Southern } \\
\text { California (EE.UU.) }\end{array}$ & $0,00 \%$ & $0,00 \%$ & $0,00 \%$ & $0,70 \%$ & $0,00 \%$ & $0,00 \%$ & $0,70 \%$ \\
\hline $\begin{array}{l}\text { Universidad Autonoma de San } \\
\text { Luis Potosí (México) }\end{array}$ & $0,00 \%$ & $0,00 \%$ & $0,00 \%$ & $0,00 \%$ & $0,00 \%$ & $0,70 \%$ & $0,70 \%$ \\
\hline $\begin{array}{l}\text { Universidade Federal do } \\
\text { Paraná (Brasil) }\end{array}$ & $0,00 \%$ & $0,00 \%$ & $0,00 \%$ & $0,00 \%$ & $0,35 \%$ & $0,00 \%$ & $0,35 \%$ \\
\hline $\begin{array}{l}\text { Universidade Federal } \\
\text { Fluminense (Brasil) }\end{array}$ & $0,00 \%$ & $0,00 \%$ & $0,00 \%$ & $0,00 \%$ & $0,35 \%$ & $0,00 \%$ & $0,35 \%$ \\
\hline $\begin{array}{l}\text { Universitat de València } \\
\text { (España) }\end{array}$ & $0,00 \%$ & $0,00 \%$ & $0,00 \%$ & $0,00 \%$ & $0,00 \%$ & $0,70 \%$ & $0,70 \%$ \\
\hline $\begin{array}{l}\text { Universitat Internacional de } \\
\text { Catalunya (España) }\end{array}$ & $0,00 \%$ & $0,00 \%$ & $0,00 \%$ & $0,00 \%$ & $0,00 \%$ & $1,05 \%$ & $1,05 \%$ \\
\hline $\begin{array}{l}\text { University College of Medical } \\
\text { Sciences, Guru Teg Bahadur } \\
\text { Hospital (India) }\end{array}$ & $0,00 \%$ & $0,00 \%$ & $0,00 \%$ & $0,00 \%$ & $0,00 \%$ & $0,35 \%$ & $0,35 \%$ \\
\hline $\begin{array}{l}\text { Universidad de Barcelona } \\
\text { (España) }\end{array}$ & $0,00 \%$ & $0,00 \%$ & $0,00 \%$ & $0,35 \%$ & $0,35 \%$ & $1,05 \%$ & $1,75 \%$ \\
\hline University of Belgrade (Serbia) & $0,00 \%$ & $0,00 \%$ & $0,00 \%$ & $0,00 \%$ & $0,35 \%$ & $0,00 \%$ & $0,35 \%$ \\
\hline $\begin{array}{l}\text { University of British Columbia } \\
\text { (Canada) }\end{array}$ & $0,00 \%$ & $0,00 \%$ & $0,00 \%$ & $0,00 \%$ & $0,00 \%$ & $0,35 \%$ & $0,35 \%$ \\
\hline $\begin{array}{l}\text { University of Cartagena } \\
\text { (Colombia) }\end{array}$ & $0,00 \%$ & $0,00 \%$ & $0,00 \%$ & $0,00 \%$ & $0,00 \%$ & $0,35 \%$ & $0,35 \%$ \\
\hline $\begin{array}{l}\text { Universidad de Cataluña } \\
\text { (España) }\end{array}$ & $0,00 \%$ & $0,00 \%$ & $0,00 \%$ & $0,00 \%$ & $0,35 \%$ & $0,00 \%$ & $0,35 \%$ \\
\hline $\begin{array}{l}\text { University of Colorado Health } \\
\text { Sciences Center (EE.UU.) }\end{array}$ & $0,00 \%$ & $0,00 \%$ & $0,35 \%$ & $0,00 \%$ & $0,00 \%$ & $0,00 \%$ & $0,35 \%$ \\
\hline
\end{tabular}


Anexo 2. Afiliación de los primeros autores firmantes de los artículos seleccionados y su porcentaje de producción global por década entre 1960 y 2017.

\begin{tabular}{|c|c|c|c|c|c|c|c|}
\hline \multirow{2}{*}{ Institución } & \multicolumn{7}{|c|}{ Décadas } \\
\hline & 1960-1969 & 1970-1979 & 1980-1989 & 1990-1999 & 2000-2009 & 2010-2017 & $1960-2017$ \\
\hline University of Cuibá MT (Brasil) & $0,00 \%$ & $0,00 \%$ & $0,00 \%$ & $0,00 \%$ & $0,00 \%$ & $0,35 \%$ & $0,35 \%$ \\
\hline $\begin{array}{l}\text { University of Detroit School of } \\
\text { Dentistry (EE.UU.) }\end{array}$ & $0,35 \%$ & $0,00 \%$ & $0,00 \%$ & $0,00 \%$ & $0,00 \%$ & $0,00 \%$ & $0,35 \%$ \\
\hline University of Florida (EE.UU.) & $0,00 \%$ & $0,00 \%$ & $0,00 \%$ & $0,00 \%$ & $0,70 \%$ & $0,35 \%$ & $1,05 \%$ \\
\hline University of Gazi (Turquía) & $0,00 \%$ & $0,00 \%$ & $0,00 \%$ & $0,00 \%$ & $0,00 \%$ & $0,35 \%$ & $0,35 \%$ \\
\hline University of Illinois (EE.UU.) & $0,00 \%$ & $0,00 \%$ & $0,00 \%$ & $0,00 \%$ & $0,00 \%$ & $0,35 \%$ & $0,35 \%$ \\
\hline University of lowa (EE.UU.) & $0,00 \%$ & $0,00 \%$ & $0,00 \%$ & $0,00 \%$ & $1,05 \%$ & $0,35 \%$ & $1,40 \%$ \\
\hline $\begin{array}{l}\text { University of Kentucky } \\
\text { (EE.UU.) }\end{array}$ & $0,00 \%$ & $0,00 \%$ & $0,00 \%$ & $0,00 \%$ & $0,00 \%$ & $0,35 \%$ & $0,35 \%$ \\
\hline University of Lagos (Nigeria) & $0,00 \%$ & $0,00 \%$ & $0,00 \%$ & $0,00 \%$ & $0,00 \%$ & $0,35 \%$ & $0,35 \%$ \\
\hline $\begin{array}{l}\text { University of Lund, School of } \\
\text { Dentistry (Suecia) }\end{array}$ & $0,00 \%$ & $0,35 \%$ & $0,00 \%$ & $0,00 \%$ & $0,00 \%$ & $0,00 \%$ & $0,35 \%$ \\
\hline University of Malta (Malta) & $0,00 \%$ & $0,00 \%$ & $0,00 \%$ & $0,00 \%$ & $0,00 \%$ & $0,35 \%$ & $0,35 \%$ \\
\hline $\begin{array}{l}\text { University of Marmara } \\
\text { (Turquía) }\end{array}$ & $0,00 \%$ & $0,00 \%$ & $0,00 \%$ & $0,00 \%$ & $0,00 \%$ & $0,35 \%$ & $0,35 \%$ \\
\hline $\begin{array}{l}\text { University of Maryland Dental } \\
\text { School (EE.UU.) }\end{array}$ & $0,00 \%$ & $0,00 \%$ & $0,00 \%$ & $0,00 \%$ & $0,35 \%$ & $0,00 \%$ & $0,35 \%$ \\
\hline $\begin{array}{l}\text { University of Melbourne } \\
\text { (EE.UU.) }\end{array}$ & $0,00 \%$ & $0,35 \%$ & $0,00 \%$ & $0,00 \%$ & $0,35 \%$ & $0,00 \%$ & $0,70 \%$ \\
\hline $\begin{array}{l}\text { University of Meryland Dental } \\
\text { School (EE.UU.) }\end{array}$ & $0,00 \%$ & $0,00 \%$ & $0,00 \%$ & $0,00 \%$ & $0,00 \%$ & $0,70 \%$ & $0,70 \%$ \\
\hline $\begin{array}{l}\text { University of Michigan } \\
\text { (EE.UU.) }\end{array}$ & $0,00 \%$ & $0,00 \%$ & $0,00 \%$ & $0,00 \%$ & $0,00 \%$ & $1,39 \%$ & $1,39 \%$ \\
\hline $\begin{array}{l}\text { Universidad de Murcia } \\
\text { (España) }\end{array}$ & $0,00 \%$ & $0,00 \%$ & $0,00 \%$ & $0,00 \%$ & $0,35 \%$ & $0,70 \%$ & $1,05 \%$ \\
\hline $\begin{array}{l}\text { University of Newcastle Upon } \\
\text { Tyne (Reino Unido) }\end{array}$ & $0,00 \%$ & $0,00 \%$ & $0,00 \%$ & $0,00 \%$ & $0,70 \%$ & $0,00 \%$ & $0,70 \%$ \\
\hline $\begin{array}{l}\text { University of North Carolina } \\
\text { (EE.UU.) }\end{array}$ & $0,00 \%$ & $0,00 \%$ & $0,35 \%$ & $0,35 \%$ & $0,00 \%$ & $0,00 \%$ & $0,70 \%$ \\
\hline University of Sao Paulo (Brasil) & $0,00 \%$ & $0,00 \%$ & $0,00 \%$ & $0,00 \%$ & $0,70 \%$ & $1,74 \%$ & $2,44 \%$ \\
\hline $\begin{array}{l}\text { University of Texas Dental } \\
\text { Branch (EE.UU.) }\end{array}$ & $0,00 \%$ & $0,35 \%$ & $0,00 \%$ & $0,00 \%$ & $0,00 \%$ & $0,00 \%$ & $0,35 \%$ \\
\hline $\begin{array}{l}\text { University of Texas Health } \\
\text { Science Center at San Antonio } \\
\text { (EE.UU.) }\end{array}$ & $0,00 \%$ & $0,00 \%$ & $0,70 \%$ & $0,35 \%$ & $0,00 \%$ & $0,00 \%$ & $1,05 \%$ \\
\hline $\begin{array}{l}\text { University of the Pacific School } \\
\text { of Dentistry (EE.UU.) }\end{array}$ & $0,00 \%$ & $0,00 \%$ & $0,00 \%$ & $0,00 \%$ & $0,35 \%$ & $0,00 \%$ & $0,35 \%$ \\
\hline University of Toronto (Canadá) & $0,00 \%$ & $0,00 \%$ & $0,00 \%$ & $0,00 \%$ & $0,70 \%$ & $0,70 \%$ & $1,40 \%$ \\
\hline $\begin{array}{l}\text { University of Wales College of } \\
\text { Medicine Dental School (Reino } \\
\text { Unido) }\end{array}$ & $0,00 \%$ & $0,00 \%$ & $0,00 \%$ & $0,00 \%$ & $0,35 \%$ & $0,00 \%$ & $0,35 \%$ \\
\hline $\begin{array}{l}\text { University of Washington } \\
\text { (EE.UU.) }\end{array}$ & $0,00 \%$ & $0,00 \%$ & $0,70 \%$ & $0,00 \%$ & $0,00 \%$ & $0,35 \%$ & $1,05 \%$ \\
\hline
\end{tabular}




\section{Anexo 2. Afiliación de los primeros autores firmantes de los artículos seleccionados} y su porcentaje de producción global por década entre 1960 y 2017.

\begin{tabular}{|c|c|c|c|c|c|c|c|}
\hline \multirow{2}{*}{ Institución } & \multicolumn{7}{|c|}{ Décadas } \\
\hline & $1960-1969$ & $1970-1979$ & 1980-1989 & 1990-1999 & $2000-2009$ & 2010-2017 & $1960-2017$ \\
\hline $\begin{array}{l}\text { University of Washington } \\
\text { School of Dentistry (EE.UU.) }\end{array}$ & $0,35 \%$ & $0,00 \%$ & $0,00 \%$ & $0,35 \%$ & $0,00 \%$ & $0,00 \%$ & $0,70 \%$ \\
\hline University of Zurich (Suiza) & $0,00 \%$ & $0,00 \%$ & $0,00 \%$ & $0,00 \%$ & $0,35 \%$ & $0,00 \%$ & $0,35 \%$ \\
\hline $\begin{array}{l}\text { University Witwatersrand } \\
\text { Dental Research Institute } \\
\text { (Sudáfrica) }\end{array}$ & $0,00 \%$ & $0,00 \%$ & $0,00 \%$ & $0,00 \%$ & $0,70 \%$ & $0,00 \%$ & $0,70 \%$ \\
\hline USP, Bauru (Brasil) & $0,00 \%$ & $0,00 \%$ & $0,00 \%$ & $0,00 \%$ & $0,35 \%$ & $0,00 \%$ & $0,35 \%$ \\
\hline $\begin{array}{l}\text { Clínica Universitaria Virgen de } \\
\text { la Arrixaca (España) }\end{array}$ & $0,00 \%$ & $0,00 \%$ & $0,00 \%$ & $0,00 \%$ & $0,00 \%$ & $0,70 \%$ & $0,70 \%$ \\
\hline $\begin{array}{l}\text { Virginia Commonwealth } \\
\text { University (EE.UU.) }\end{array}$ & $0,00 \%$ & $0,00 \%$ & $0,00 \%$ & $0,00 \%$ & $0,00 \%$ & $0,35 \%$ & $0,35 \%$ \\
\hline Vishnu Dental College (India) & $0,00 \%$ & $0,00 \%$ & $0,00 \%$ & $0,00 \%$ & $0,00 \%$ & $0,35 \%$ & $0,35 \%$ \\
\hline $\begin{array}{l}\text { Vrije Universiteit Brussel } \\
\text { (Bélgica) }\end{array}$ & $0,00 \%$ & $0,00 \%$ & $0,00 \%$ & $0,00 \%$ & $0,00 \%$ & $0,35 \%$ & $0,35 \%$ \\
\hline $\begin{array}{l}\text { Yonsei University (Corea del } \\
\text { Sur) }\end{array}$ & $0,00 \%$ & $0,00 \%$ & $0,00 \%$ & $0,00 \%$ & $0,00 \%$ & $0,70 \%$ & $0,70 \%$ \\
\hline Práctica privada & $0,00 \%$ & $0,00 \%$ & $0,00 \%$ & $0,00 \%$ & $0,35 \%$ & $3,14 \%$ & $3,49 \%$ \\
\hline Total & $1,75 \%$ & $2,10 \%$ & $4,90 \%$ & $4,89 \%$ & $22,02 \%$ & $64,34 \%$ & $100,00 \%$ \\
\hline
\end{tabular}


Anexo 3. Número de citas recibidas por artículo.

\begin{tabular}{|c|c|c|}
\hline Década & Autor & Citas \\
\hline \multirow[t]{5}{*}{ 1960-1969 } & Law D. (1964) & 15 \\
\hline & Speeding y cols. (1965) & 17 \\
\hline & Beaver y cols. (1966) & 26 \\
\hline & Redig DF. (1968) & 30 \\
\hline & Sayegh FS. (1968) & 5 \\
\hline \multirow[t]{5}{*}{ 1970-1979 } & Koch y Nyborg (1970) & 9 \\
\hline & Koch y Nyborg (1970) & 9 \\
\hline & Ranly y Lazzari (1978) & 10 \\
\hline & Wright y Widmer (1979) & 4 \\
\hline & Halofsky y cols. (1979) & 0 \\
\hline \multirow[t]{16}{*}{ 1980-1989 } & Fuks y Bimstein (1981) & 26 \\
\hline & Boeve y Dermaut (1982) & 62 \\
\hline & Fuks y cols. (1983) & 9 \\
\hline & Ruemping y cols. (1983) & 12 \\
\hline & Ranly D. (1984) & 8 \\
\hline & Lekka y cols. (1984) & 10 \\
\hline & Verco y Allen (1984) & 5 \\
\hline & Shoji y cols. (1985) & 43 \\
\hline & Hicks y cols. (1986) & 21 \\
\hline & Shulman y cols. (1987) & 9 \\
\hline & Ranly y cols. (1987) & 3 \\
\hline & Garcia-Godoy y Ranly (1987) & 0 \\
\hline & Sheller y Morton (1987) & 5 \\
\hline & Prakash y cols. (1989) & 10 \\
\hline & Alacam A. (1989) & 12 \\
\hline & Alacam A. (1989) & 9 \\
\hline \multirow[t]{14}{*}{ 1990-1999 } & Fuks y cols. (1990) & 17 \\
\hline & Fei y cols. (1991) & 50 \\
\hline & Gentner y cols. (1991) & 1 \\
\hline & Fuks y Eidelman (1991) & 22 \\
\hline & Oztas y cols. (1994) & 0 \\
\hline & Ranly DM. (1994) & 52 \\
\hline & Roberts JF. (1996) & 17 \\
\hline & Fishman y cols. (1996) & 20 \\
\hline & Fuks y cols. (1997) & 65 \\
\hline & Prabhu y Munshi (1997) & 6 \\
\hline & Cotes y cols. (1997) & 14 \\
\hline & Davina AB. (1998) & 4 \\
\hline & Elliott y cols. (1999) & 32 \\
\hline & Liu y cols. (1999) & 2 \\
\hline
\end{tabular}


Anexo 3. Número de citas recibidas por artículo.

\begin{tabular}{|c|c|c|}
\hline Década & Autor & Citas \\
\hline \multirow[t]{38}{*}{ 2000-2009 } & Ibricevic y Al-Jame (2000) & 27 \\
\hline & Waterhouse y cols. (2000) & 37 \\
\hline & Papagiannoulis L. (2002) & 22 \\
\hline & Dean y cols. (2002) & 33 \\
\hline & Fuks AB. (2002) & 68 \\
\hline & Cleaton-Jones y cols. (2002) & 2 \\
\hline & Guelmann y cols. (2002) & 20 \\
\hline & Ibricevic y Al-Jame (2003) & 42 \\
\hline & Hunter ML. (2003) & 6 \\
\hline & Casas y cols. (2003) & 17 \\
\hline & Nadine y cols. (2003) & 0 \\
\hline & Kalaskar y Damle (2004) & 16 \\
\hline & Agamy y cols. (2004) & 109 \\
\hline & Loh y cols. (2004) & 46 \\
\hline & AAPD (2004) & 4 \\
\hline & Saltzman y cols. (2005) & 38 \\
\hline & Markovic y cols. (2005) & 45 \\
\hline & Holan y cols. (2005) & 120 \\
\hline & Naik y Hegde (2005) & 71 \\
\hline & Butani y cols. (2005) & 11 \\
\hline & Guelmann y cols. (2005) & 17 \\
\hline & Vargas y Packham (2005) & 22 \\
\hline & Farsi y cols. (2005) & 79 \\
\hline & Vargas y cols. (2006) & 18 \\
\hline & Liu JF. (2006) & 1 \\
\hline & Srinivasan y cols. (2006) & 35 \\
\hline & Patchett y cols. (2006) & 17 \\
\hline & Rodd y cols. (2006) & 20 \\
\hline & Fuks y Papagiannoulis (2006) & 11 \\
\hline & Asián-Gonzales y cols. (2007) & 9 \\
\hline & Cortes y cols. (2007) & 3 \\
\hline & Peng y cols. (2007) & 32 \\
\hline & Sabbarini y cols. (2007) & 12 \\
\hline & Moretti y cols. (2007) & 10 \\
\hline & Aeinehchi y cols. (2007) & 53 \\
\hline & Hingston y cols. (2007) & 10 \\
\hline & Aminabadi y cols. (2008) & 6 \\
\hline & Sonmez y cols. (2008) & 60 \\
\hline
\end{tabular}


Anexo 3. Número de citas recibidas por artículo.

\begin{tabular}{|c|c|c|}
\hline \multirow[t]{17}{*}{ Década } & Autor & Citas \\
\hline & Bahrololoomi y cols. (2008) & 16 \\
\hline & Toomarian y cols. (2008) & 0 \\
\hline & Coll J. (2008) & 29 \\
\hline & Milnes AR. (2008) & 17 \\
\hline & Zurn y Seale (2008) & 29 \\
\hline & Ng y Messer (2008) & 18 \\
\hline & Ng y Messer (2008) & 28 \\
\hline & Moretti AB. (2008) & 67 \\
\hline & Fuks A. (2008) & 44 \\
\hline & Adlakha y cols. (2009) & 0 \\
\hline & Chin y cols. (2009) & 1 \\
\hline & Ferreira y cols. (2009) & 9 \\
\hline & De Menezes y cols. (2009) & 14 \\
\hline & Rao y cols. (2009) & 13 \\
\hline & Subramaniam y cols. (2009) & 27 \\
\hline & Steffen y Waes (2009) & 16 \\
\hline \multirow[t]{22}{*}{ 2010-2017 } & Gupta y cols. (2010) & 2 \\
\hline & Hegde y Battepati (2010) & 0 \\
\hline & Zealand y cols. (2010) & 22 \\
\hline & Ansari y Ranjpour (2010) & 28 \\
\hline & Doyle y cols. (2010) & 22 \\
\hline & Simancas-Pallares y cols.(2010) & 25 \\
\hline & Kurji y cols. (2011) & 4 \\
\hline & Kurji y cols. (2011) & 6 \\
\hline & Gisoure EF. (2011) & 0 \\
\hline & Guelmann y cols. (2011) & 8 \\
\hline & Liu y cols. (2011) & 18 \\
\hline & Boj y cols. (2011) & 11 \\
\hline & Nematollahi y cols. (2011) & 2 \\
\hline & Lima y cols. (2011) & 8 \\
\hline & Malekafzali y cols. (2011) & 26 \\
\hline & Srinivasan y Jayanthi (2011) & 17 \\
\hline & Vosatek y cols. (2011) & 15 \\
\hline & Erdem y cols. (2011) & 30 \\
\hline & Ratnakumari y Thomas (2012) & 0 \\
\hline & Haghgoo y Abassi (2012) & 4 \\
\hline & Shayegan y cols. (2012) & 22 \\
\hline & Frenkel y cols. (2012) & 4 \\
\hline
\end{tabular}


Anexo 3. Número de citas recibidas por artículo.

\begin{tabular}{|c|c|c|}
\hline Década & Autor & Citas \\
\hline & Odabas y cols. (2012) & 13 \\
\hline & Airen y cols. (2012) & 11 \\
\hline & Sushynsky y cols. (2012) & 18 \\
\hline & Yaman y cols. (2012) & 11 \\
\hline & Omar y cols. (2012) & 4 \\
\hline & Bowen y cols. (2012) & 10 \\
\hline & Howley y cols. (2012) & 6 \\
\hline & Trairatvorakul y Koothiratrakarn (2012) & 13 \\
\hline & De Coster y cols. (2013) & 12 \\
\hline & Ruby y cols. (2013) & 9 \\
\hline & Bijimole y cols. (2013) & 1 \\
\hline & Oliveira y cols. (2013) & 23 \\
\hline & Fernández y cols. (2013) & 13 \\
\hline & Mettlach y cols. (2013) & 6 \\
\hline & Mehrdad y cols. (2013) & 4 \\
\hline & Anthonappa y cols. (2013) & 11 \\
\hline & Subay y cols. (2013) & 5 \\
\hline & Al-Mutairi y Bawazir (2013) & 5 \\
\hline & Shabzendedar y cols. (2013) & 10 \\
\hline & EK Hui Derksen y cols. (2013) & 0 \\
\hline & Jayam y cols. (2014) & 6 \\
\hline & Mohammad y cols. (2014) & 1 \\
\hline & Marghalani y cols. (2014) & 11 \\
\hline & Yadav y cols. (2014) & 9 \\
\hline & Akacy y Sari (2014) & 9 \\
\hline & AAPD. (2014) & 18 \\
\hline & De Rossi y cols. (2014) & 34 \\
\hline & Yildiz y Tosun (2014) & 11 \\
\hline & Asgary y cols. (2014) & 8 \\
\hline & Durmus y Tanboga (2014) & 11 \\
\hline & Shirvani y cols. (2014) & 8 \\
\hline & Lin y cols. (2014) & 30 \\
\hline & Khorakian y cols. (2014) & 9 \\
\hline & Kang y cols. (2015) & 10 \\
\hline & Parisay y cols. (2015) & 0 \\
\hline & Pimenta y cols. (2015) & 0 \\
\hline & Omar S. (2015) & 2 \\
\hline & Mohammad y Baroudi (2015) & 1 \\
\hline & Kusum y cols. (2015) & 0 \\
\hline
\end{tabular}


Anexo 3. Número de citas recibidas por artículo.

\begin{tabular}{|c|c|c|}
\hline Década & Autor & Citas \\
\hline & Fernandes y cols. (2015) & 17 \\
\hline & Lourenço y cols. (2015) & 3 \\
\hline & Niranjani y cols. (2015) & 18 \\
\hline & Lee y cols. (2015) & 14 \\
\hline & Kenchappa y cols. (2015) & 0 \\
\hline & Olatosi y cols. (2015) & 7 \\
\hline & Stringhini y cols. (2015) & 10 \\
\hline & Gupta y cols. (2015) & 0 \\
\hline & Marques N. (2015) & 8 \\
\hline & Marques y cols. (2015) & 2 \\
\hline & Martens y cols. (2015) & 8 \\
\hline & Al-Dlaigan YH. (2015) & 0 \\
\hline & Farsi y cols. (2015) & 5 \\
\hline & Camilleri J. (2015) & 33 \\
\hline & Bhagat y cols. (2016) & 0 \\
\hline & Togaru y cols. (2016) & 0 \\
\hline & Goyal y cols. (2016) & 0 \\
\hline & Yildirim y cols. (2016) & 11 \\
\hline & Uloopi y cols. (2016) & 5 \\
\hline & Musale y Soni (2016) & 0 \\
\hline & Grewal y cols. (2016) & 0 \\
\hline & El Meligy y cols. (2016) & 6 \\
\hline & Daltoé y cols. (2016) & 11 \\
\hline & Al-Haj Ali SN. (2016) & 0 \\
\hline & Wunsch y cols. (2016) & 0 \\
\hline & Cuadros-Fernández y cols. (2016) & 16 \\
\hline & Godhi y Tyagi (2016) & 0 \\
\hline & Gonzalez-Lara y cols. (2016) & 5 \\
\hline & Dhar y cols. (2017) & 18 \\
\hline & Ozmen y Bayrak (2017) & 11 \\
\hline & Kathal y cols. (2017) & 0 \\
\hline & Beretta y Federici (2017) & 0 \\
\hline & Sunitha y cols. (2017) & 0 \\
\hline & Purohit y cols. (2017) & 0 \\
\hline & Juneja y Kulkarni (2017) & 1 \\
\hline & Patidar y cols. (2017) & 0 \\
\hline & Collado-González y cols. (2017) & 4 \\
\hline & Hugar y cols. (2017) & 0 \\
\hline
\end{tabular}


Anexo 3. Número de citas recibidas por artículo.

\begin{tabular}{|c|c|c|}
\hline Década & Autor & Citas \\
\hline & Kalra y cols. (2017) & 1 \\
\hline & Sirohi y cols. (2017) & 0 \\
\hline & Chauhan y cols. (2017) & 0 \\
\hline & Bakhtiar y cols. (2017) & 1 \\
\hline & Keles y Kocaturk (2017) & 0 \\
\hline & Hugar y cols. (2017) & 2 \\
\hline & Shafie y cols. (2017) & 0 \\
\hline & Coll y cols. (2017) & 9 \\
\hline & Sivadas y cols. (2017) & 1 \\
\hline & Rajasekharan y cols. (2017) & 12 \\
\hline & Monteiro y cols. (2017) & 0 \\
\hline & Bani y cols. (2017) & 5 \\
\hline
\end{tabular}

Fuente: Web Of Science [Internet]. Madrid: Fundación Española para la Ciencia y la Tecnología;2001- [Consultado 15 noviembre 2017] Disponible en: www.fecyt.es. 